\title{
Trainee-led research using an integrated knowledge translation or other research partnership approaches: a scoping review
}

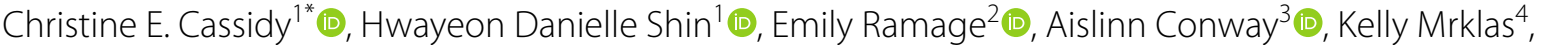 \\ Celia Laur ${ }^{5}$, Amy Beck ${ }^{6}$, Melissa Demery Varin ${ }^{7} \mathbb{0}$, Sandy Steinwender ${ }^{8}$, Tram Nguyen $^{9}$, Jodi Langley ${ }^{10}$, \\ Rachel Dorey ${ }^{11}$, Lauren Donnelly ${ }^{11}$ and $\|$ lja Ormel ${ }^{12}$
}

\begin{abstract}
Background: There are increasing expectations for researchers and knowledge users in the health system to use a research partnership approach, such as integrated knowledge translation, to increase the relevance and use of research findings in health practice, programmes and policies. However, little is known about how health research trainees engage in research partnership approaches such as IKT. In response, the purpose of this scoping review was to map and characterize the evidence related to using an IKT or other research partnership approach from the perspective of health research trainees in thesis and/or postdoctoral work.

Methods: We conducted this scoping review following the Joanna Briggs Institute methodology and Arksey and O'Malley's framework. We searched the following databases in June 2020: MEDLINE, Embase, CINAHL and PsycINFO. We also searched sources of unpublished studies and grey literature. We reported our findings in accordance with the Preferred Reporting Items for Systematic Reviews and Meta-Analyses Extension for Scoping Reviews.

Results: We included 74 records that described trainees' experiences using an IKT or other research partnership approach to health research. The majority of studies involved collaboration with knowledge users in the research question development, recruitment and data collection stages of the research process. Intersecting barriers to IKT or other research partnerships at the individual, interpersonal and organizational levels were reported, including lack of skills in partnership research, competing priorities and trainees'"outsider" status. We also identified studies that evaluated their IKT approach and reported impacts on partnership formation, such as valuing different perspectives, and enhanced relevance of research.
\end{abstract}

Conclusion: Our review provides insights for trainees interested in IKT or other research partnership approaches and offers guidance on how to apply an IKT approach to their research. The review findings can serve as a basis for future reviews and primary research focused on IKT principles, strategies and evaluation. The findings can also inform IKT training efforts such as guideline development and academic programme development.

Keywords: Integrated knowledge translation, Health research, Research trainees, Partnership approaches, Collaborative research

${ }^{*}$ Correspondence: ccassidy@dal.ca

1 School of Nursing, Dalhousie University, Halifax, NS, Canada

Full list of author information is available at the end of the article

\section{Introduction}

Collaborative research approaches, such as coproduction, codesign, engaged scholarship and integrated knowledge translation (IKT) [1], aim to produce relevant original author(s) and the source, provide a link to the Creative Commons licence, and indicate if changes were made. The images or other third party material in this article are included in the article's Creative Commons licence, unless indicated otherwise in a credit line to the material. If material is not included in the article's Creative Commons licence and your intended use is not permitted by statutory regulation or exceeds the permitted use, you will need to obtain permission directly from the copyright holder. To view a copy of this licence, visit http://creativecommons.org/licenses/by/4.0/. The Creative Commons Public Domain Dedication waiver (http://creativeco mmons.org/publicdomain/zero/1.0/) applies to the data made available in this article, unless otherwise stated in a credit line to the data. 
research findings to address healthcare issues. IKT, specifically, focuses on making research more useful through research partnerships. IKT is defined as "a model of collaborative research, where researchers work with knowledge users who identify a problem and have the authority to implement the research recommendations" [2]. Studies have shown that use of an IKT approach improves the quality of research [3], enhances value for research among decision-makers [4], increases capacity among decision-makers for engaging in research [4-6], and creates more impactful and useful research findings $[3,7$, 8]. Research partnerships have been shown to be critical during the COVID-19 pandemic, as patients, citizens, healthcare providers, researchers, policy-makers and health system leaders from around world have come together to collectively address this global crisis [9].

Despite the value of IKT and other research partnership approaches, studies report many challenges in establishing and maintaining research partnerships with knowledge users $[3,4,10]$. Significant time is needed to develop trusting, authentic relationships, and there may be insufficient resources to support partnership development and maintenance [10]. Further, differing needs and priorities among researchers and health system decision-makers $[3,4,10]$, as well as unclear goals, roles and expectations, can hinder research partnerships [4].

Health system leaders have identified a lack of researcher preparation for engaging in collaborative partnerships as a significant barrier to successful research partnerships [11]. This can lead to ineffective researcher behaviour (e.g., mismatch of researcher interests and organizational needs, lack of researcher understanding of health system context, lack of respect) and affect the development of positive, mutually beneficial research partnerships [11]. Other studies have shown that researchers require specific knowledge and skills for working in partnership with health system decisionmakers [12]. However, researchers often do not have the opportunity to learn how to establish effective research partnerships with knowledge users in the health system [10].

Specific training in IKT or other research partnerships is needed to promote collaborative health research moving forward. Most graduate students do not receive formal training in collaborative health research approaches $[13,14]$. Efforts are needed to support trainees, defined as graduate students (master's, doctoral) and postdoctoral fellows, in developing an understanding of health system context and skills to engage in collaborative research partnerships $[11,15]$. Such training efforts are essential to support trainees in building trusting, effective relationships with knowledge users to foster meaningful, ethical research with relevant outcomes [16].
Currently, the IKT or research partnership literature describes strategies, barriers and facilitators to research partnerships from the perspective of researchers and knowledge users [10, 11, 17-19]. However, little is known about how trainees engage in research partnership approaches such as IKT. This is needed as a first step to inform research trainees on the use of IKT or other research partnership approaches and future academic training modernization efforts. As such, the purpose of this scoping review was to map and characterize the evidence related to using an IKT or other research partnership approach from the perspective of health research trainees in thesis and/or postdoctoral work.

\section{Methods}

We conducted this scoping review following the Joanna Briggs Institute (JBI) methodology [20, 21] and Arksey and O'Malley's framework [22]. Our a priori protocol has been published previously [23]. This full report followed the Preferred Reporting Items for Systematic Reviews and Meta-Analysis Extension for Scoping Reviews (PRISMA-ScR) checklist [24] (Additional File 2).

\section{Stage 1: Identifying the research question}

We conducted a scoping review to map and characterize the available evidence related to using an IKT approach or other research partnership approach from the perspectives of trainees in thesis and/or postdoctoral work. Specifically, we answered the following research question:

1. How have IKT or other research partnership approaches been applied in thesis and/or postdoctoral health research?

Additional research objectives included:

a. Identifying IKT/research partnership principles, strategies and/or tools used in trainee- led health research

b. Identifying barriers and facilitators to using IKT or other research partnership approaches in trainee-led health research

c. Identifying if/how outcomes were reported and evaluated in trainee-led health research using IKT or other research partnership approaches.

\section{Stage 2: Identifying relevant studies Participant}

This review considered literature for which health research trainees (i.e., graduate students [master's, doctoral] and postdoctoral fellows) were the primary author/researcher of the paper. Postdoctoral fellows 
were described as postdoctoral researchers or postdoctoral research associates. Students/fellows in the position of a trainee meant that the included studies were related to the student's or fellow's thesis/programme project/dissertation/fellowship projects.

\section{Concept}

This review considered studies that explored IKT or other research partnership approaches in trainee-led health research. We included studies that described the trainee's experience with IKT research or related partnership approaches (i.e., manuscript or thesis/dissertation chapter that provides a reflection or description of the approach, text or opinion paper describing how the partnership approach was used). Included papers explained how the research partnerships approach was used, including principles, strategies and/or tools. Studies that stated the use of a research partnership approach but did not describe how it was used were excluded. Studies that described barriers and facilitators to using an IKT or other research partnership approach were included. Studies that evaluated the IKT approach were also included. Papers that did not describe a research study were excluded as wrong design. For this review, we used the following operational terms and definitions (Table 1).

\section{Context}

We considered literature focused on trainee-led health research. For the purpose of this review, health research referred to research that aimed to "increase our knowledge of health, disease, and health services, and to then apply that knowledge to help people lead healthier lives" [25]. It also included "biomedical research, epidemiological studies, and health services research, as well as studies of behavioral, social, and economic factors that affect health" [26].

\section{Search strategy}

In collaboration with a health science librarian, we developed a search strategy to locate both published and unpublished primary studies, reviews, and text and opinion papers. Hoekstra and colleagues' [27] comprehensive search strategy for synthesizing the research partnership literature was used to inform our search strategy. We followed the three-step process in accordance with the JBI Scoping Review Methodology. First, we conducted an initial limited search of MEDLINE and CINAHL to identify articles on the topic. Second, from the selected articles, we derived relevant text words and index terms to develop a full search strategy. Third, the search strategy, including all identified keywords and index terms, was adapted for all included information sources. We searched the following databases on 24 June 2020: MEDLINE (Ovid), Embase (Elsevier), CINAHL (EBSCO) and PsycINFO (EBSCO). The final search strategy for each database can be found in Additional file 1. We included peer-reviewed studies, editorials and commentaries. We also searched sources of unpublished studies and grey literature (not empirical studies) including ProQuest Dissertation \& Theses Global databases (ProQuest) and the first 50 pages of Google Scholar during the period of September-November 2020. Only papers published in English were included. No date limits were applied, to allow for exploration of the use of IKT or other research partnership approaches in trainee-led research over time. We also used websites of research and academic institutions and health system organizations, together with concept papers, reports and blog posts, that reported non-peer-reviewed literature. We searched relevant websites of professional bodies or organizations such as the Integrated Knowledge Translation Research Network (IKTRN), Strategy for Patient-Oriented Research (SPOR) SUPPORT [Support for People and Patient-Oriented Research and Trials] Units, National Institutes of Health (NIH) Dissemination \& Implementation, National Institute for Health Research (NIHR) Collaborations

Table 1 Operational terms and definitions

\begin{tabular}{|c|c|}
\hline Term & Definition \\
\hline Integrated knowledge translation & $\begin{array}{l}\text { "A model of collaborative research, where researchers work with knowledge users who identify a problem } \\
\text { and have the authority to implement the research recommendations" [2] }\end{array}$ \\
\hline Research partnerships & $\begin{array}{l}\text { "Individuals, groups, or organizations engaged in collaborative research activity involving at least one } \\
\text { researcher (e.g., individual affiliated with an academic institution) and any stakeholder actively engaged in } \\
\text { any part of the research process (e.g., decision or policy-maker, health care administrator or leader, com- } \\
\text { munity agency, charities, network, patients, lived experience advisor, etc.)" [144] }\end{array}$ \\
\hline Approaches & The IKT and research partnership activities that comprise or promote collaboration in the research process \\
\hline Barrier & "A circumstance or obstacle that keeps people or things apart or prevents communication or progress" [145] \\
\hline Facilitator & "Someone or something that facilitates (to make easier)" [146] \\
\hline
\end{tabular}


for Leadership in Applied Health Research and Care (CLAHRCs), and KT Canada, and we also contacted individuals or groups for additional material (i.e., Twitter, IKTRN members, relevant KT listservs). We used our professional networks in the area of IKT and collaborative health research to email relevant content experts to identify additional sources that met the inclusion criteria. Reference chaining was conducted with all included papers.

\section{Stage 3: Study selection}

All identified citations were collated and uploaded into Covidence [28], and duplicates were automatically removed. A pair of reviewers (CC, HDS, JL, CL, ER, $\mathrm{KM}, \mathrm{MDV}$ ) independently screened and assessed titles and abstracts against the inclusion criteria. Next, fulltext articles were retrieved for potentially relevant studies. After screening titles and abstracts, two independent reviewers (CC, HDS, JL, CL, ER, KM, MDV) assessed the full text of relevant studies in detail against the inclusion criteria. Any discrepancies between the reviewers at each stage of the study selection process were resolved through discussion or by a third reviewer. We sought out the trainee status of each primary author during the fulltext assessment stage. When papers did not mention a primary author's status, we searched the author's name and the indicated affiliation in Google. If the primary author was found to be a trainee, we included the paper. We also made use of available LinkedIn profiles of the authors to identify their trainee status.

\section{Stage 4: Charting data}

We developed a data extraction tool to capture information on the general characteristics of the included paper, trainees' characteristics, IKT approaches, the trainee-reported barriers and facilitators to knowledge user engagement, and outcomes. Two reviewers (CC, HDS) first pilot-tested the extraction tool on three studies to identify any discrepancies and ensure consistency of data extraction. Then reviewers (CC, HDS, JL, TN, $\mathrm{ER}, \mathrm{AB}, \mathrm{AC}, \mathrm{RD}, \mathrm{LD}, \mathrm{MDV}$ ) were paired and independently extracted data using Covidence. Conflicts between reviewers regarding data extracted were resolved through discussion or by a third reviewer.

We used several frameworks to analyse the extracted data. First, we mapped included papers onto the seven phases of the knowledge-to-action (KTA) cycle [29] based on the reported research purpose and objectives. Second, we categorized the knowledge users' engagement into the five levels of public participation of the International Association for Public Participation (IAP2) spectrum to help conceptualize the data and offer a structure for reporting the results [30]. Third, we identified the research stages [31] that knowledge users were engaged in, including (1) development of research question, (2) development of research proposal, (3) pre-study launch administration, (4) recruitment and data collection, (5) data analysis, and (6) dissemination and implementation. Fourth, we used the Workgroup for Intervention Development and Evaluation Research (WIDER) [32] reporting checklist to describe details about the IKT approach, including (1) content (nature and goal of the study and/or IKT partnership); (2) mode of delivery (specific types of IKT activities in which knowledge users were involved); (3) duration and/or frequency (timing of IKT activities); (4) participants (who was involved in specific IKT activities); and (5) personnel (who coordinated or led IKT activities) (review objective A). Fifth, we used the Capability, Opportunity, and Motivation-Behaviour (COM-B) model [33] and Theoretical Domains Framework (TDF) [34] to describe trainee-reported barriers and facilitators to knowledge user engagement (review objective B). We first coded data using the COM-B and TDF, and then generated themes inductively. Next, we used McLeroy's social-ecological model [35] to map where the reported barriers and facilitators existed within the trainee's research ecosystem (i.e., individual, interpersonal and/or organizational levels). Lastly, we developed three categories informed by the IKT outcomes reported by Gagliardi $[4,36]$ to organize reported outcomes and impact of the IKT approach in the included studies (review objective C), if the studies reported outcomes. We coded reported outcomes into the following three categories: (1) immediate outcome of partnership formation (e.g., mutual understanding of language, work style, needs and constraints, and appreciation for the collaborative process are established [4]); (2) intermediate outcome of partnership that occurred during the preparation and research process (e.g., identification of research questions, and conduct of research[36]); and (3) long-term outcome of partnership at the completion of the research process and post-study (e.g., scale-up/spread of research, and use of research in practice and policy $[4,36]$.)

One reviewer (HDS) initially coded data using the coding schemes for the first five papers. This coding was verified by a second reviewer (CC) to identify any discrepancies and ensure consistency in coding. After verifying the coding strategy, one reviewer (HDS) coded the remaining data, and the second reviewer $(C C)$ verified the coded data. Findings were presented and reviewed with all team members to interpret key findings.

\section{Stage 5: Collating, summarizing and reporting results}

We charted the data in a tabular form to align with the review objectives. In addition to the tables, we created a figure of the barriers and facilitators. We also produced 
descriptive numerical summaries of the quantitative data (i.e., frequency counts). Lastly, we provided a narrative summary to accompany these presentations and described how the findings addressed the review's question and objectives.

\section{Results}

Our database searches resulted in 3237 citations. We identified an additional 23 relevant papers through other information sources (e.g., IKTRN, Google Search), for a total of 3260 citations. After duplicate removal, 2895 citations remained for assessment against the inclusion criteria. After screening titles and abstracts, 343 citations remained for full-text review, and 74 citations, describing 72 studies, were included. See Fig. 1 for the PRISMA flow chart.

\section{Characteristics of included studies and trainees}

Of the 74 papers, 34 were peer-reviewed studies, 28 were theses, 9 were web-based sources and 3 were other published grey literature. The 72 studies were a mix of participatory action research $(n=41)$, mixed or multi-methods $(n=12)$, codesign $(n=1)$, scoping or systematic review $(n=2)$ or other qualitative designs $(n=12)$. Web-based sources included casebooks from the IKTRN and text interviews of trainees who used an IKT approach in their research. Most grey literature sources were theses (i.e., primary research) and non-peer-reviewed journal articles.

Papers originated from Canada $(n=36)$, the United States $(n=23)$, Australia $(n=5)$, the United Kingdom $(n=6)$, Norway $(n=1)$, Slovenia $(n=1)$ and Iceland $(n=1)$. The trainees (primary authors of these papers) were in nursing $(n=14)$, education $(n=12)$, public or population health $(n=8)$, medicine $(n=5)$, social work $(n=5)$, physiotherapy $(n=2)$, occupational health $(n=3)$, dietetics $(n=1)$ and speech language pathology $(n=1)$. These trainees were in master's $(n=12)$, doctoral $(n=52)$ or postdoctoral $(n=6)$ training. Table 2 summarizes the overall characteristics of included papers along with trainee characteristics.

The included studies were mapped onto the KTA cycle [29] based on the reported research purpose and objectives, as follows: identify problem $(n=30)$ [37-67]; adapt knowledge to local context $(n=34)$ [37-40, 43, 44, 46, 49, $52,55,56,61,62,64,65,67-86]$; assess barriers/facilitators to knowledge use $(n=14)[39,40,52,56,63,68,72$, 74, 81, 83, 87-90]; select, tailor, implement interventions

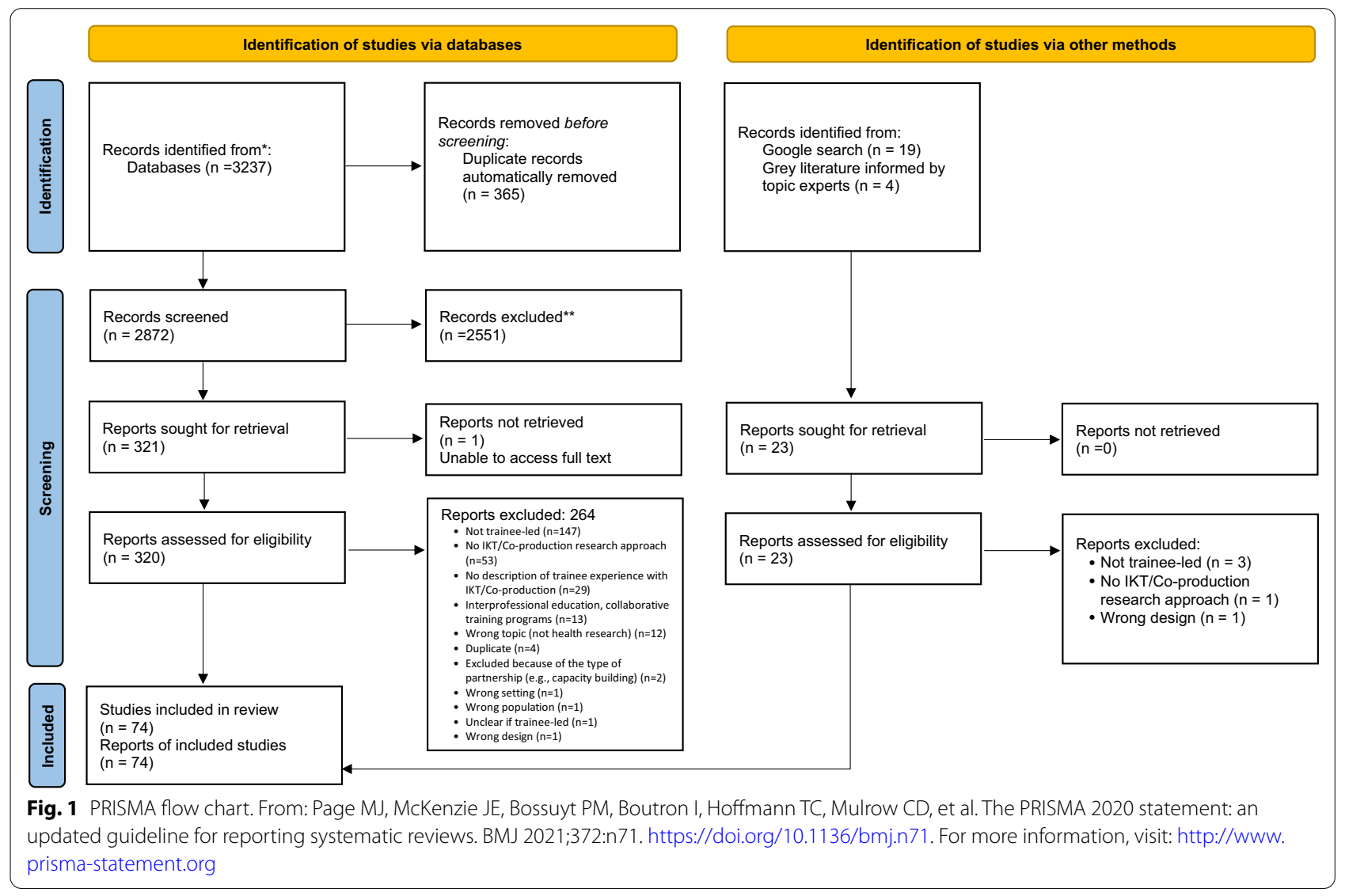




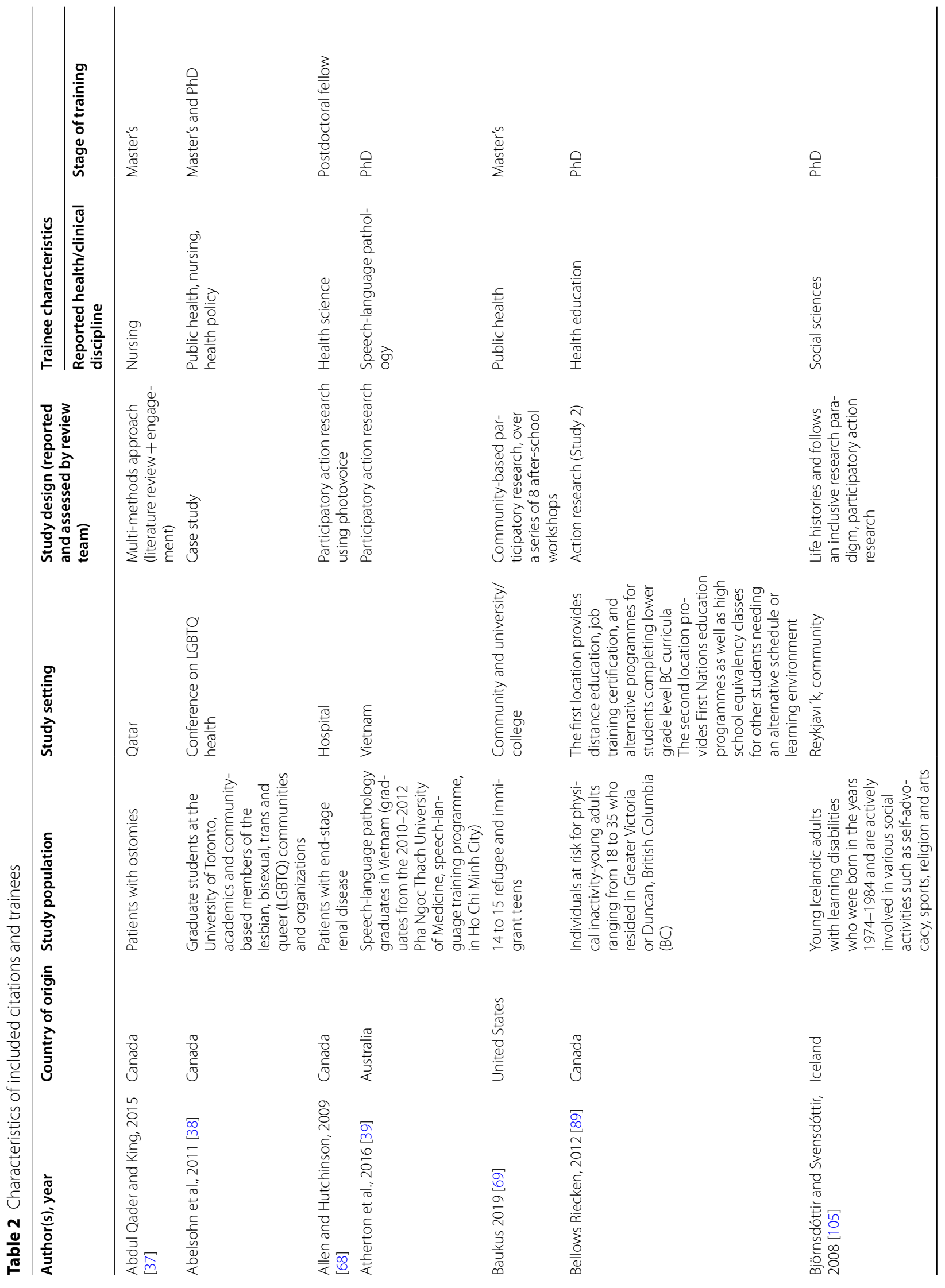




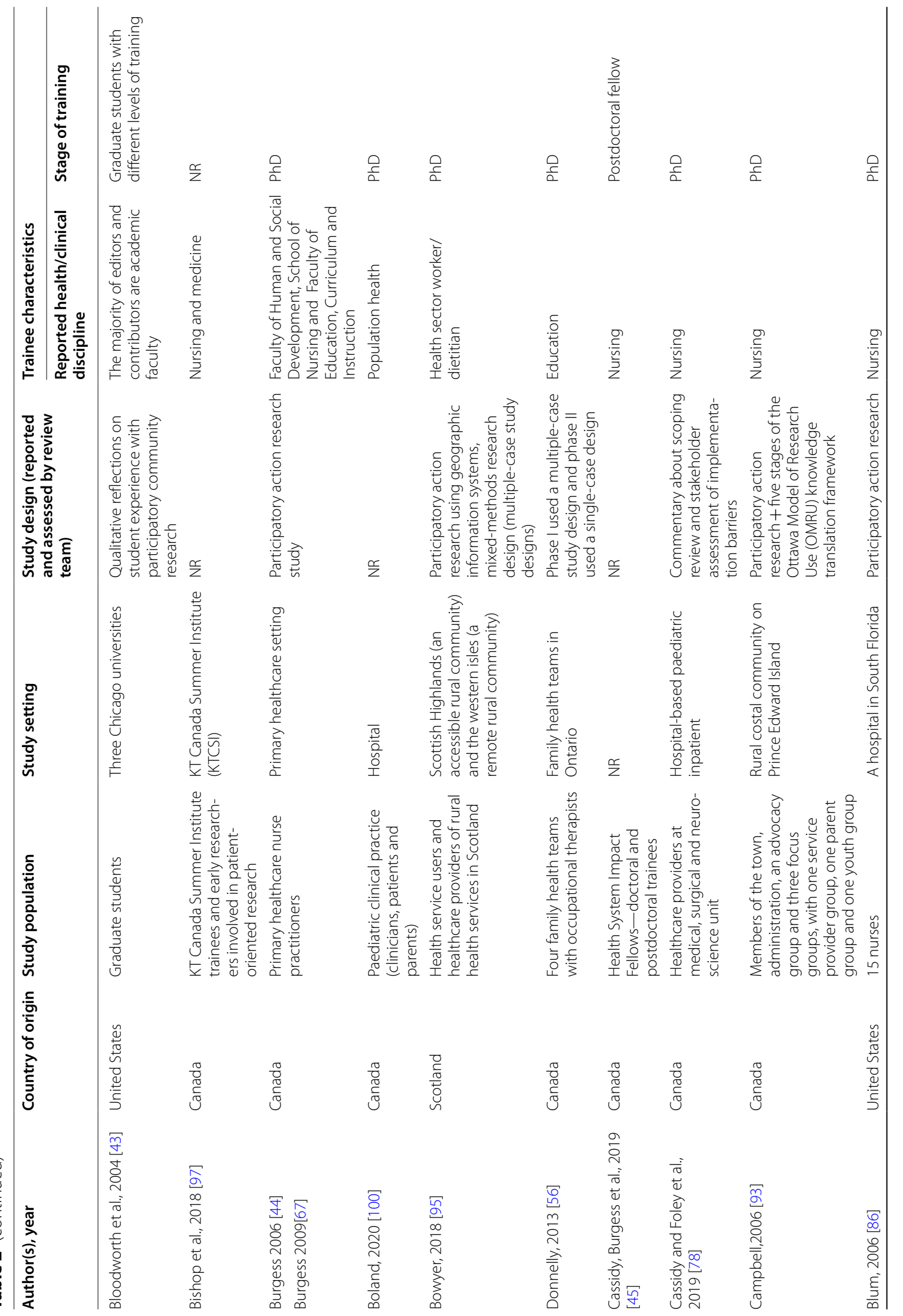




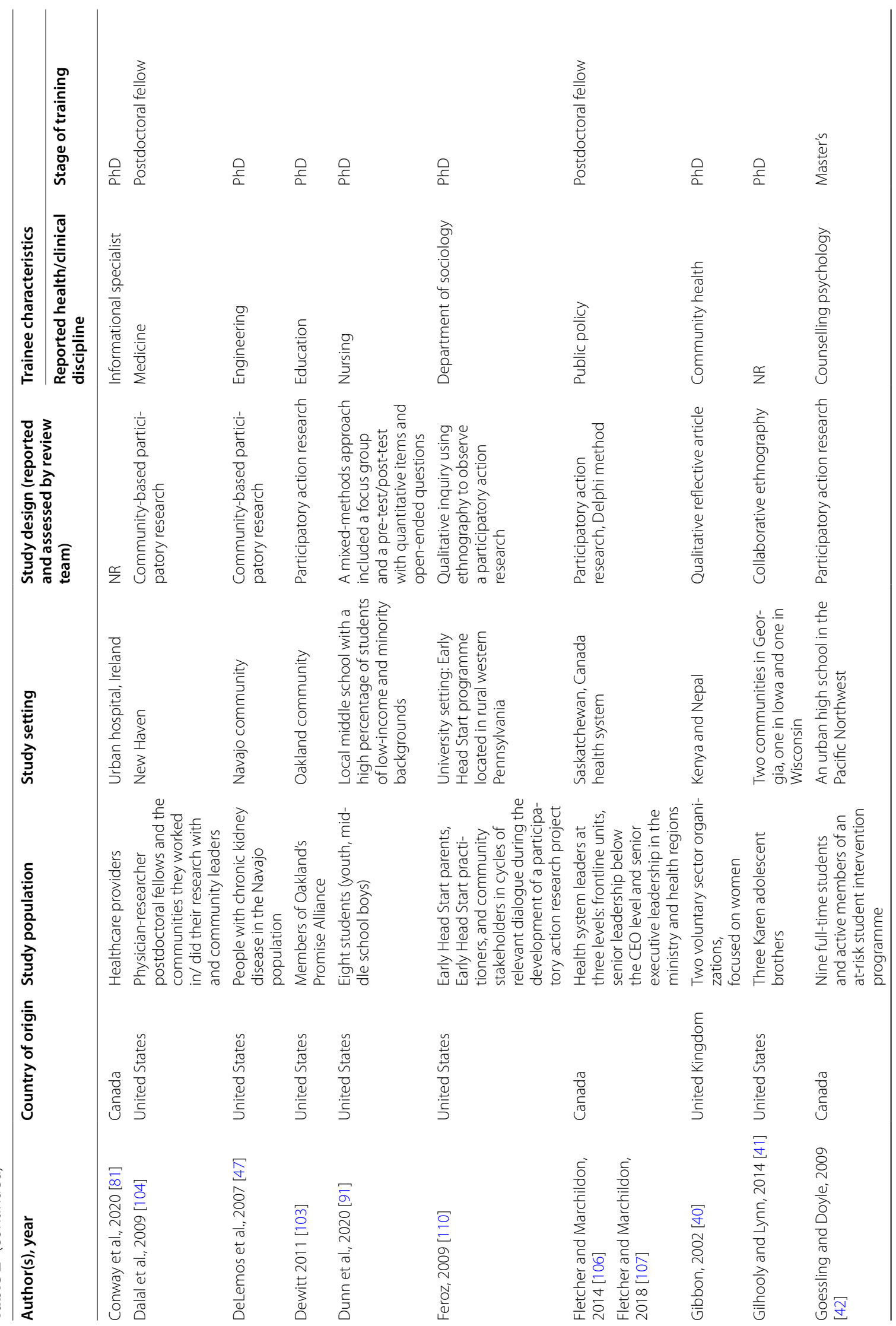




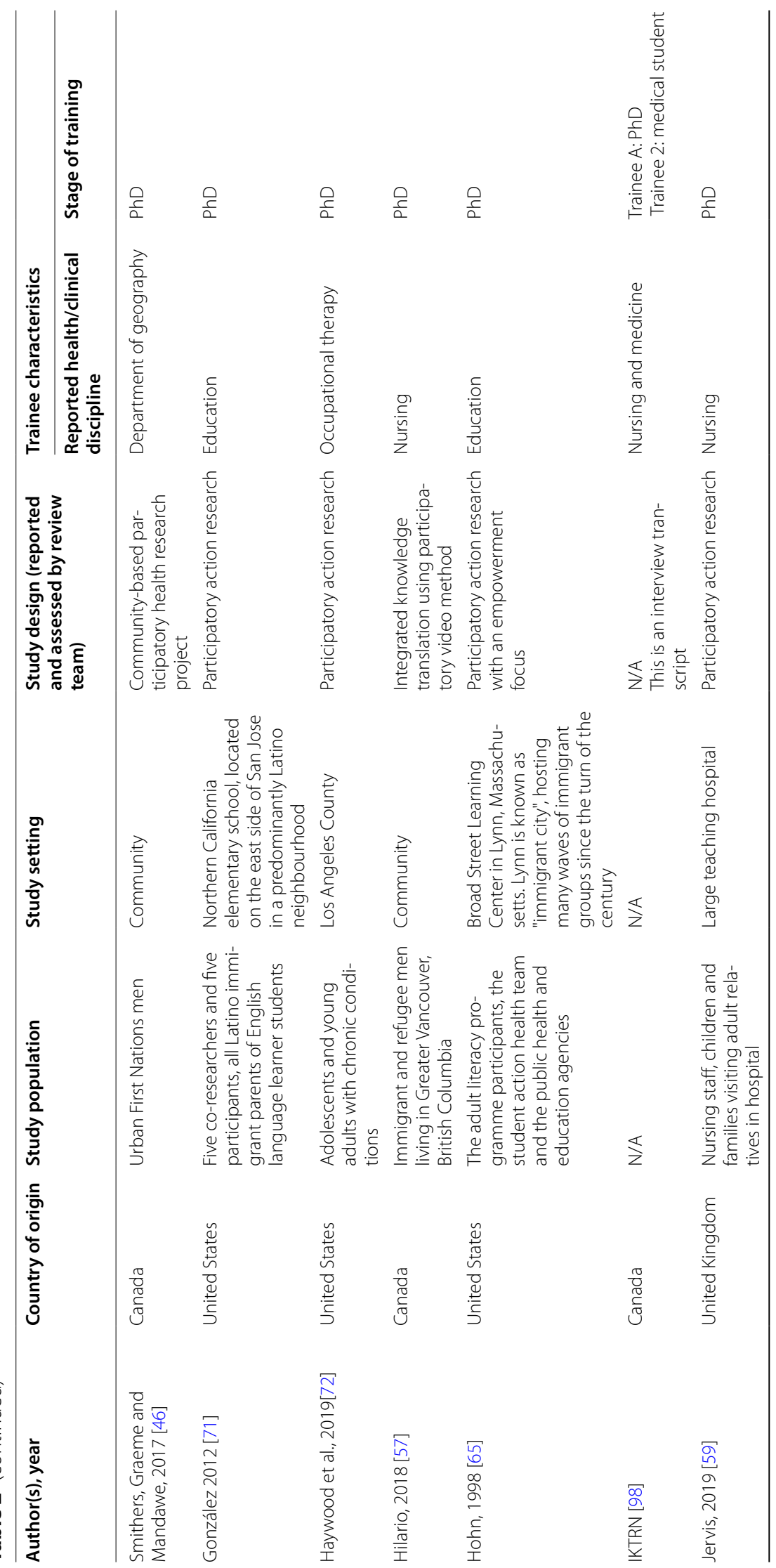




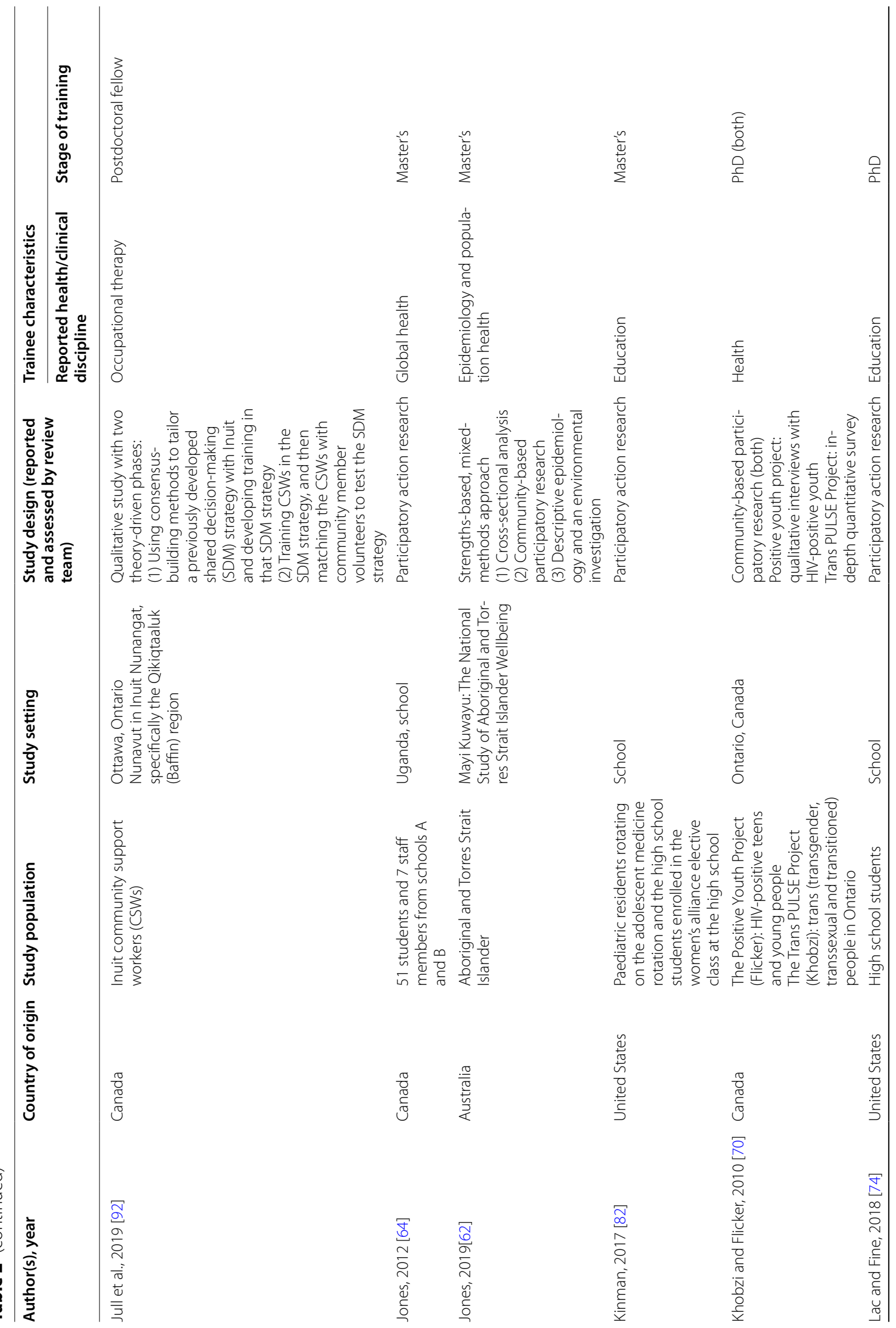




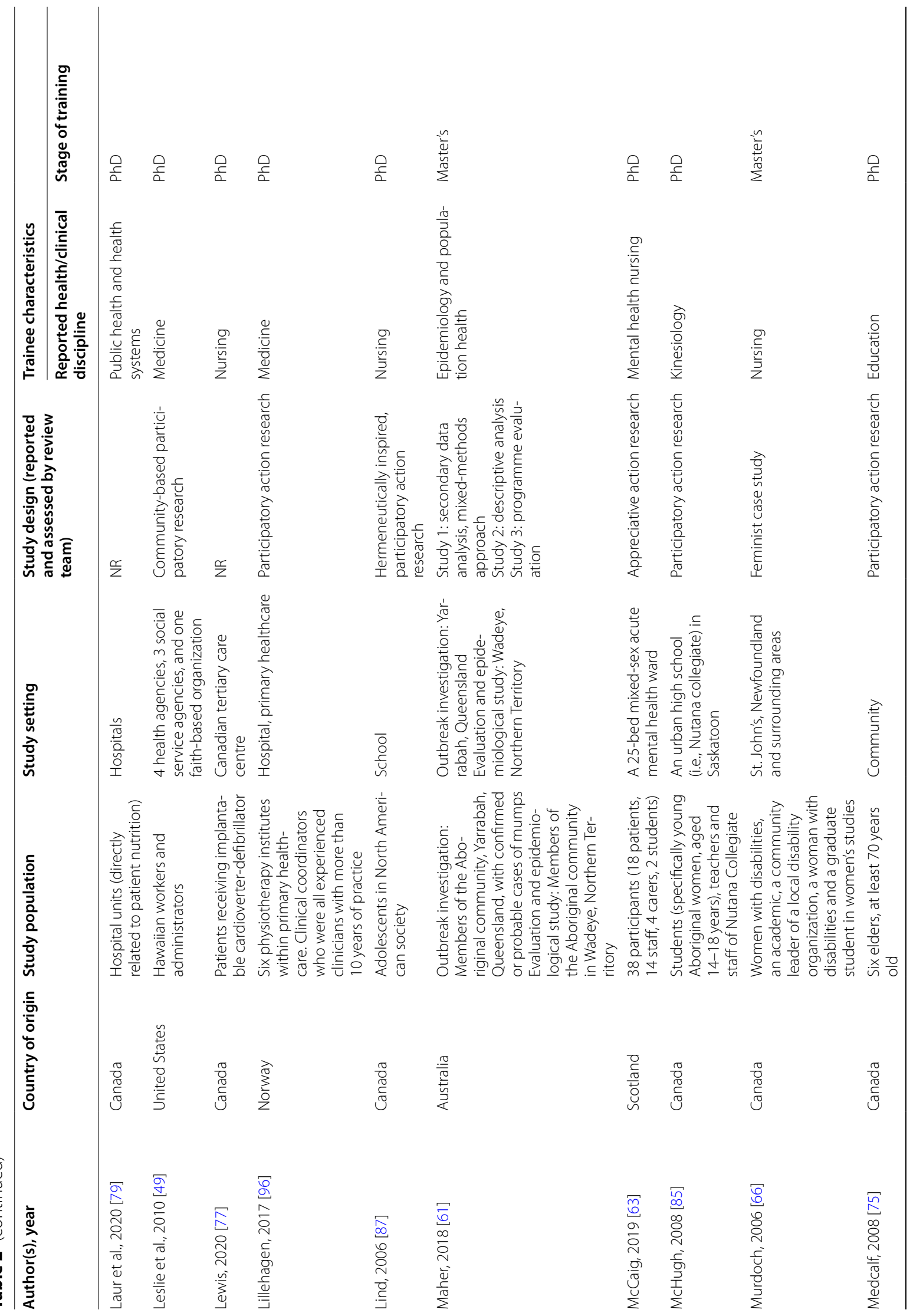




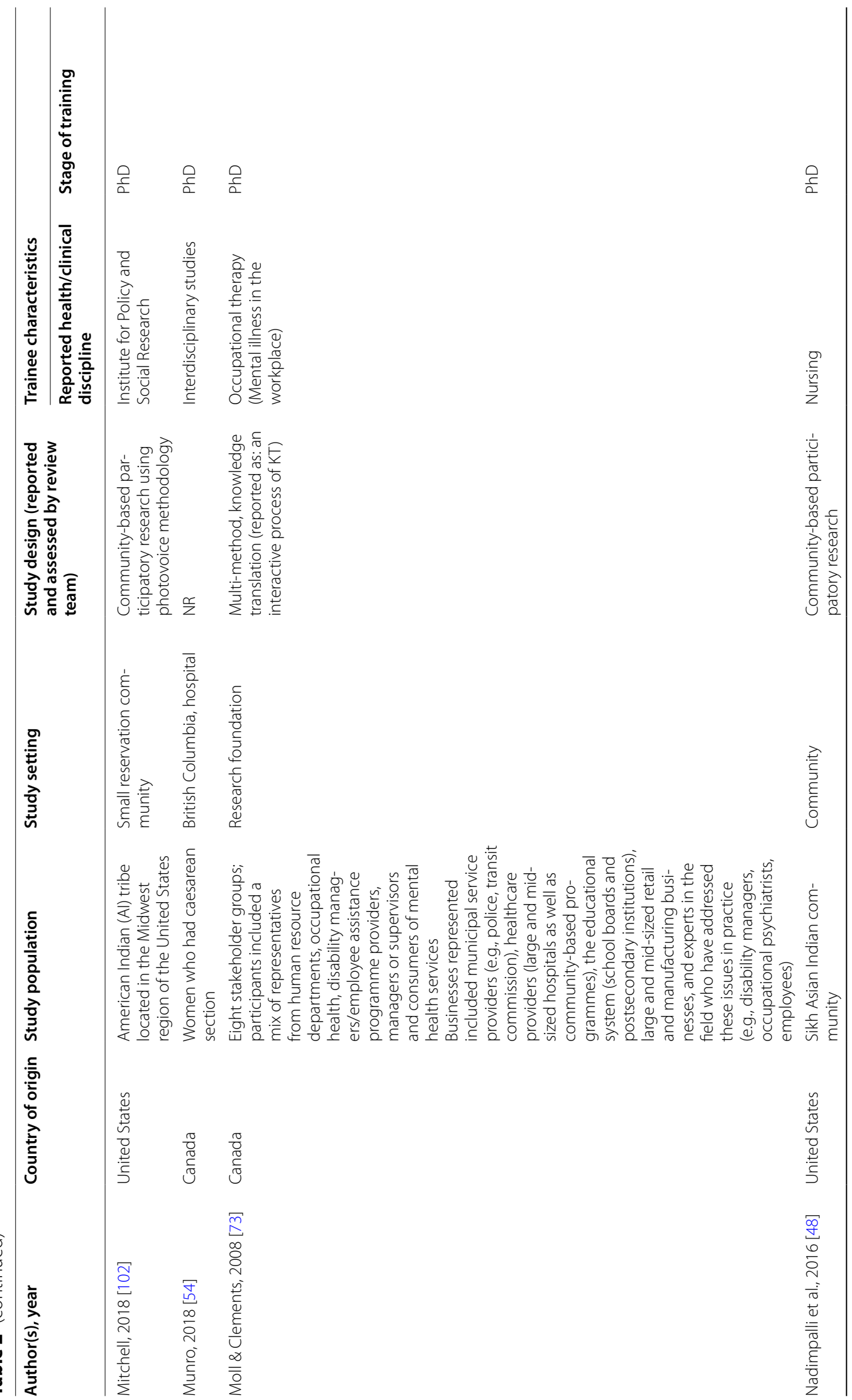




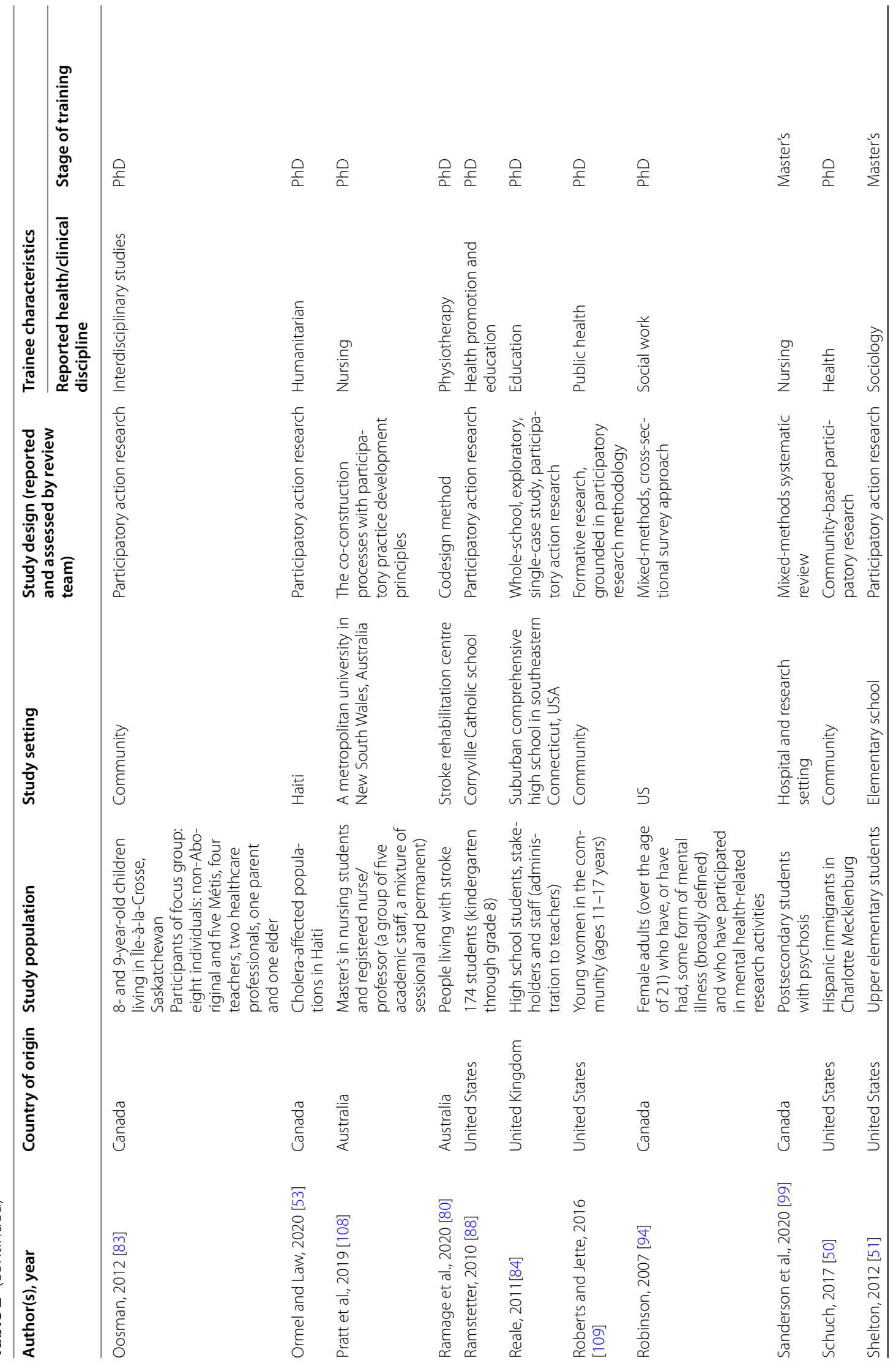




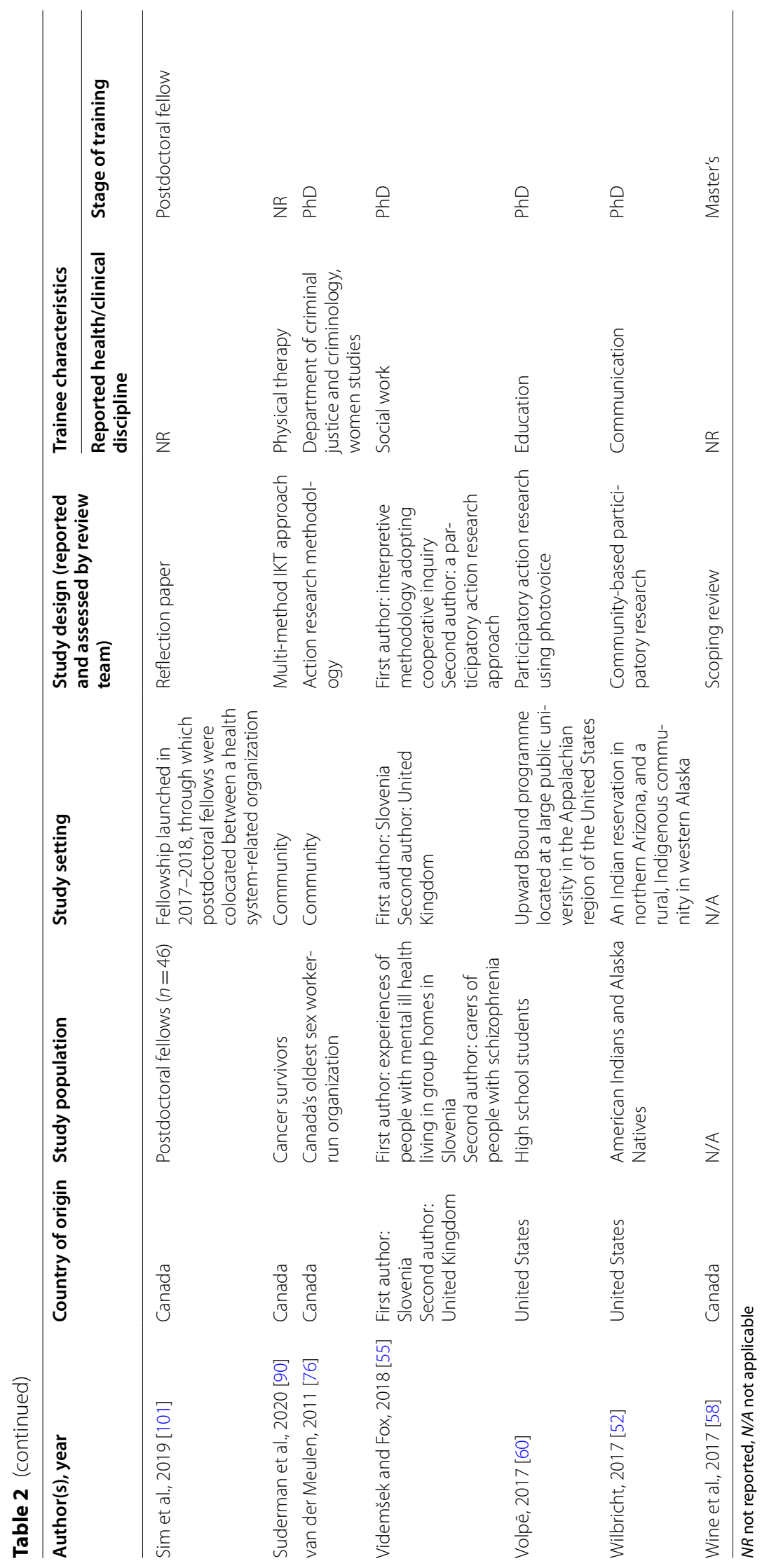


$(n=11)[56,63,68,80,81,83,88-92]$; monitor knowledge use $(n=25)$ [55, 63-65, 69, 73, 80, 83, 89, 91-107]; evaluate outcomes $(n=22)[48,50,51,62,64,68,71,79$, $83,91,93,95,100-110]$; sustain knowledge use $(n=1)$ [79]. As shown, many studies comprised more than one KTA phase. However, some papers $(n=14)[40,45,46$, 50, 51, 54, 70, 74, 80, 101, 104, 105, 108, 109] did not fit into the KTA phases, as they were more reflective in nature.

\section{Knowledge user engagement}

Knowledge users were engaged in multiple stages of research: (1) research question $(n=42)$; (2) research proposal ( $n=39)$; (3) administrative pre-launch $(n=30)$; (4) recruitment and data collection $(n=51)$; (5) data analysis $(n=45) ;(6)$ dissemination and implementation $(n=26)$. Seven studies did not report the stages of knowledge user engagement. We also recorded the level of knowledge user engagement based on the IAP2 Spectrum for Public Participation [111]: inform $(n=2)$; consult $(n=8)$; involve $(n=15)$; collaborate $(n=43)$; empower $(n=3)$. Four studies did not report the level of knowledge user engagement. See Table 3 for more detail.

\section{IKT strategies}

Overall, there was a lack of reporting on the use of IKT strategies. As detailed in Table 3, meetings were the most common mode of engagement with knowledge users $(n=27)$. Written communication, such as handouts or letters, was also used $(n=11)$, as was email $(n=7)$ and phone communication $(n=6)$.

\section{Barriers and facilitators to the IKT approach}

Table 4 summarizes the key barrier themes identified from the included papers. Trainees' lack of knowledge and skills posed challenges for IKT research [48, 71, 72, 74, 79, 84, 97, 109]. IKT knowledge and skills were related to knowing how to apply an IKT approach and specific procedural techniques related to IKT research processes. Also, trainees reported that their "outsider" status from the health system made the knowledge user engagement challenging [44, 51, 52, 67]. In terms of the IKT process, trainees reported that competing priorities among trainees (e.g., coursework, thesis/project completion), knowledge users (e.g., patient care, service delivery, resource use) and university institutions (e.g., timely thesis completion, resource use) posed challenges to the IKT approach $[62,65,70,72,78,79,94]$. Furthermore, knowledge users can have full schedules, making it difficult to find a common time to meet as a team $[47,89]$. It was also difficult for trainees to define the scope of the research project that fulfilled knowledge user needs, aligned with health system priorities, and adhered to institutional guidelines (i.e., thesis requirements) [44, 63, 67, 74, 83]. The time-limited nature of graduate programmes also posed challenges to trainees [64, 81, 99]. Trainees also experienced power dynamics within the academic and health system institutions, which further contributed to the difficulties of knowledge user engagement [44, 51, $56,72,93]$. Lastly, it was challenging to meet knowledge users in person when they lived too far and had to travel a long distance $[39,47,52]$.

Table 5 summarizes the key facilitator themes identified from the included papers. Some trainees gained the necessary knowledge and skills to undertake IKT research in specialized graduate courses focused on applied health research $[69,82]$. Similarly, trainees viewed themselves as facilitators $[39,55,65,110]$ and reported that facilitation skills helped with knowledge user engagement $[38,53,65,80,91,102]$. For example, trainees aimed to use clear and common language to facilitate knowledge user engagement activities [80]. Additionally, trainees' flexibility and problem-solving skills were helpful when engagement challenges required quick adaptations [45, $53,91]$. Trainees also reported that being an "insider" was a facilitating factor for doing IKT research [63, 76, 88, 110]. A pre-existing relationship with knowledge users or previous experience in the related field helped with building partnerships [70, 76]. Trainees also reported that trusting relationships and a safe place for partnership development were facilitating factors for knowledge user engagement $[38,50,65,66,72,80,83]$. This includes promoting a team culture that respects diverse perspectives. Trainees described using agendas and written agreements, such as a memorandum of understanding, to help set common goals early in the IKT process [65, $83,98]$. Supervisors played an important role in facilitating trainees' IKT involvement $[69,70,80,100]$. Trainees reported that having supervisors or committee members with expertise in IKT was helpful to guide them through the research partnership.

Figure 2 represents a modified illustration of McLeroy's social-ecological model [35] to help visualize where the reported barriers and facilitators exist within the trainee's research ecosystem (i.e., individual, interpersonal and organizational levels). As shown in Tables 4 and 5, barriers and facilitators have been categorized to corresponding level(s) to guide interpretation of the data. First, the individual level represents trainees themselves. Second, the interpersonal level represents people that trainees interact with, such as supervisors and knowledge users. Lastly, the organizational level represents institutions, including universities and health systems, as well as communities. Identified barriers and facilitators are not static or absolute; as represented with connected lines, some of these barriers and facilitators exist across the three 


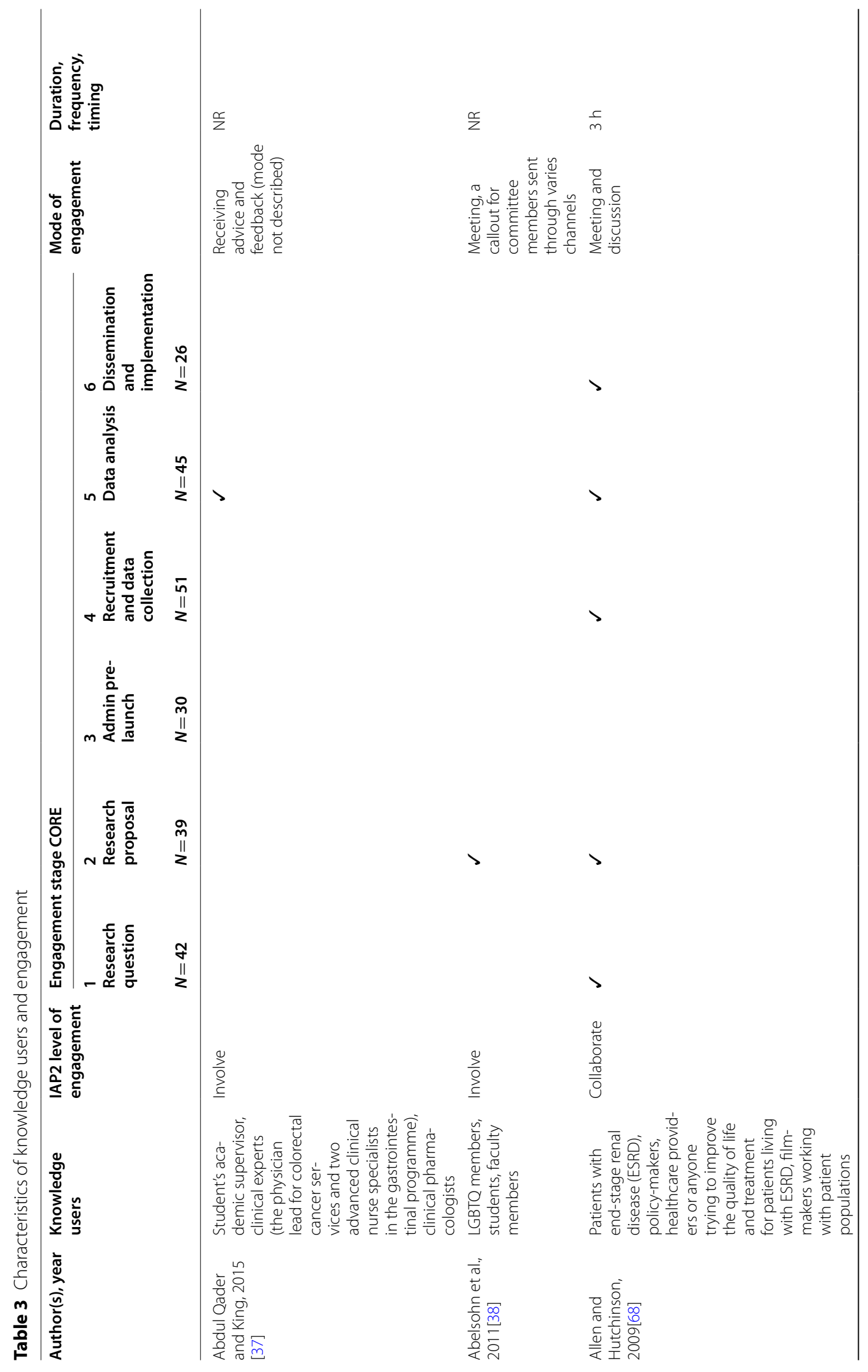




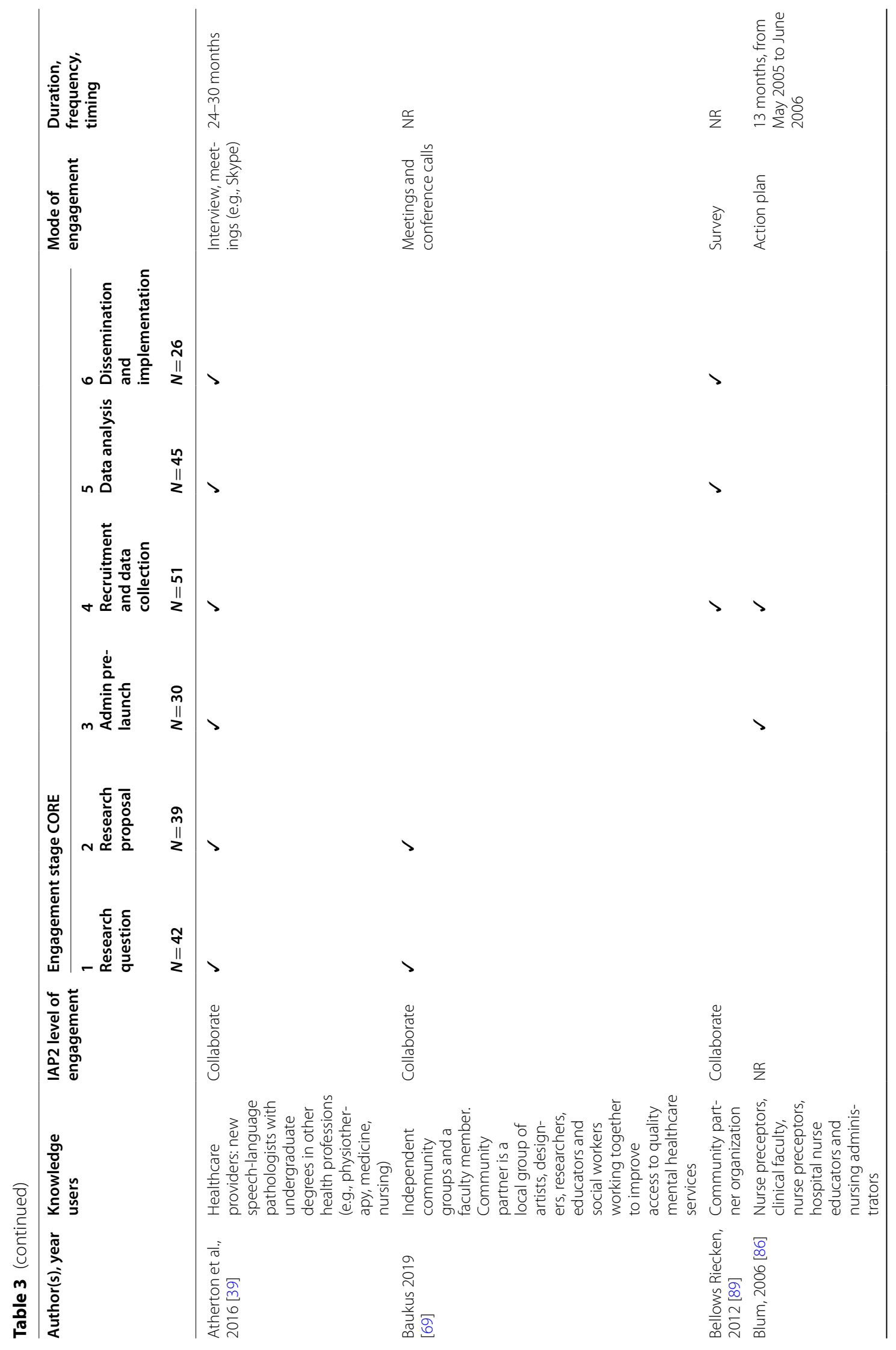




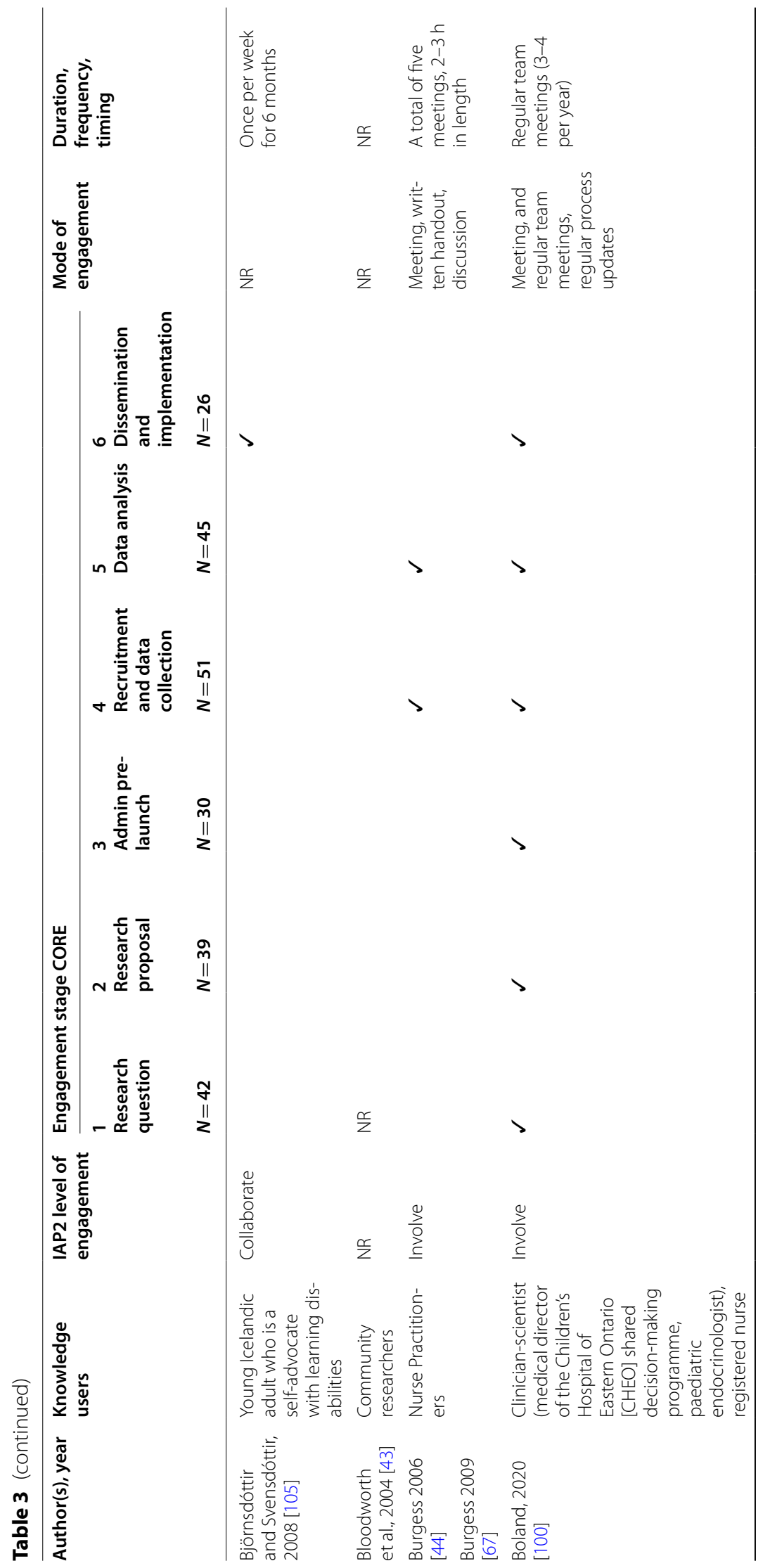




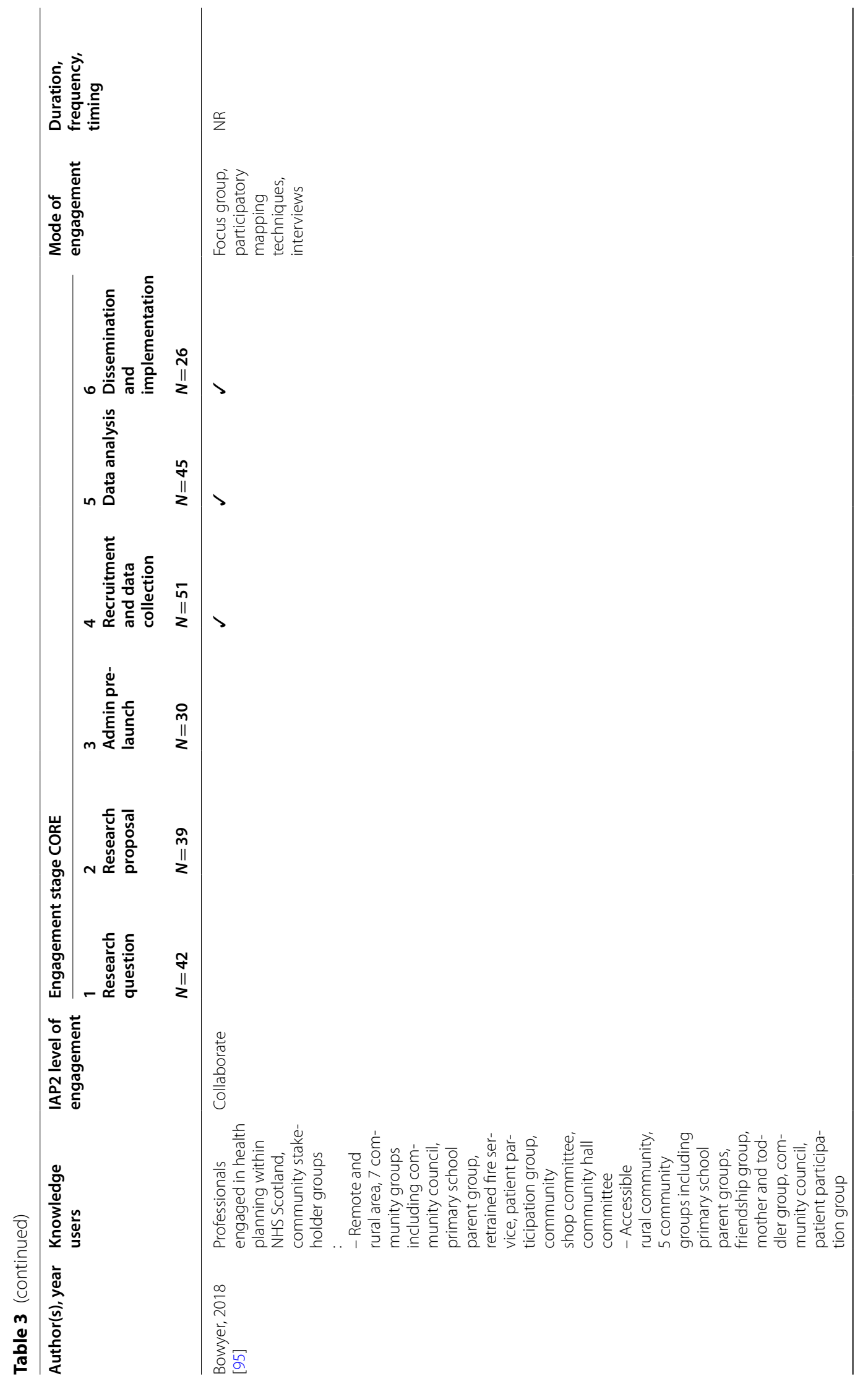




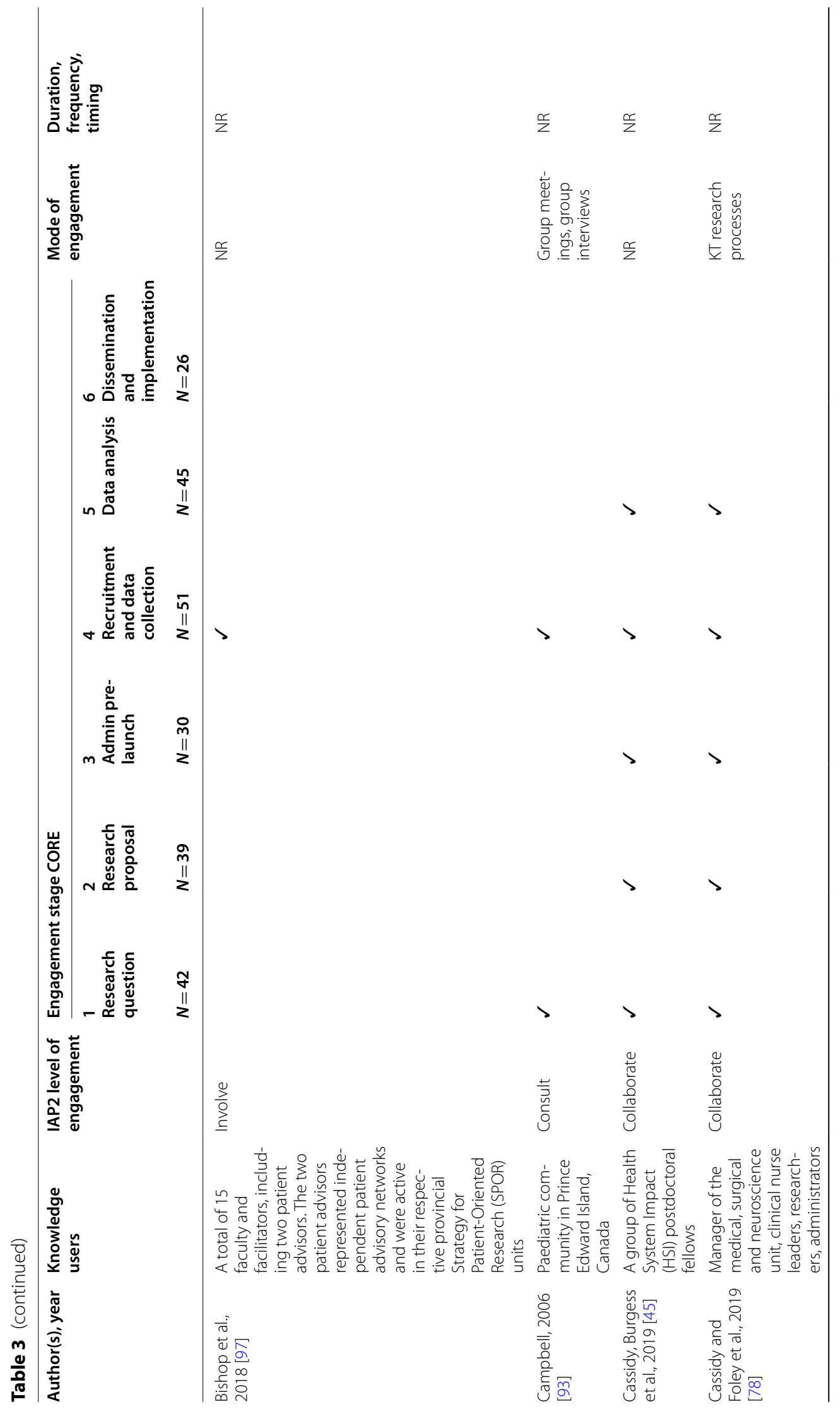




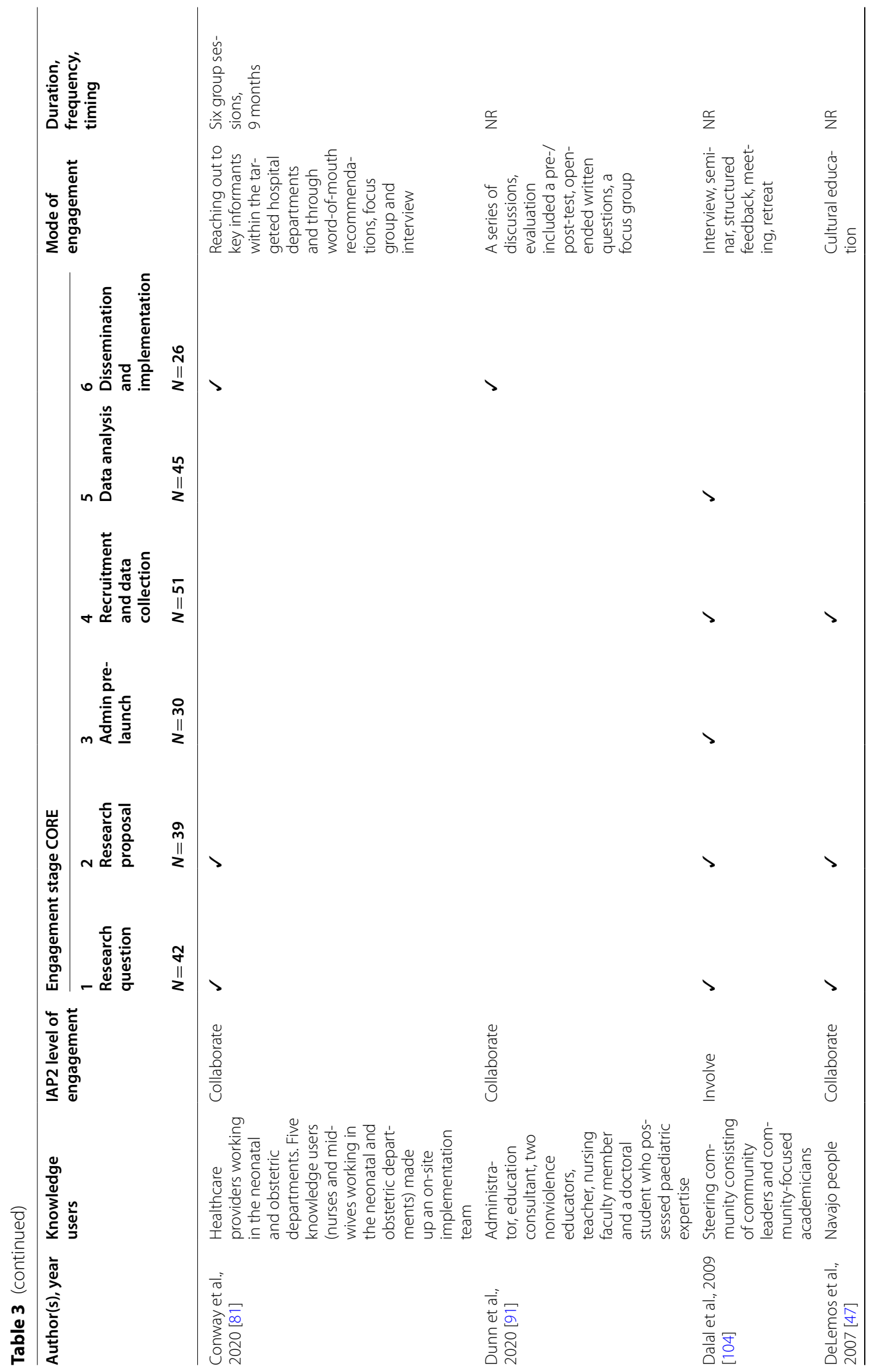




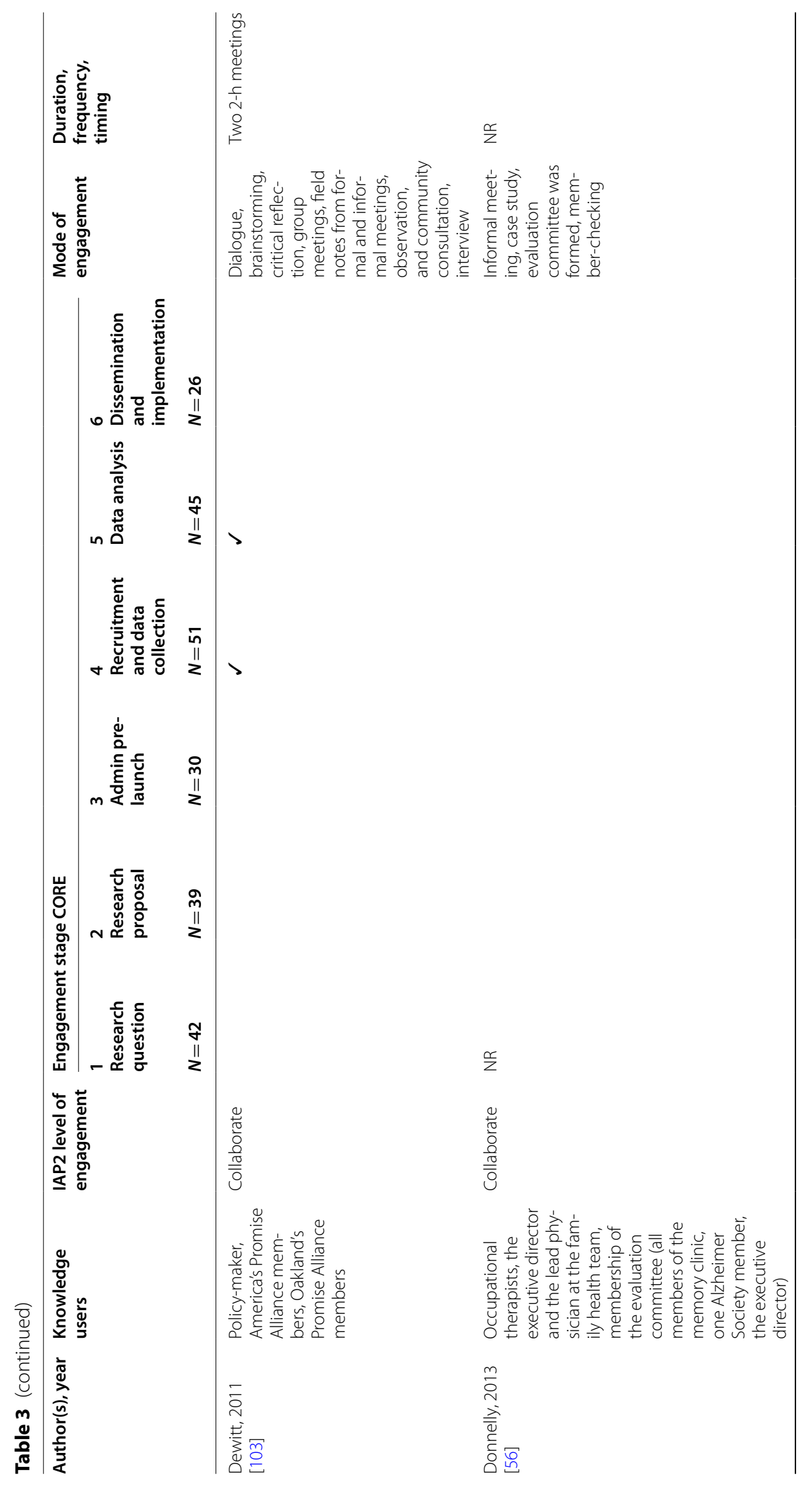




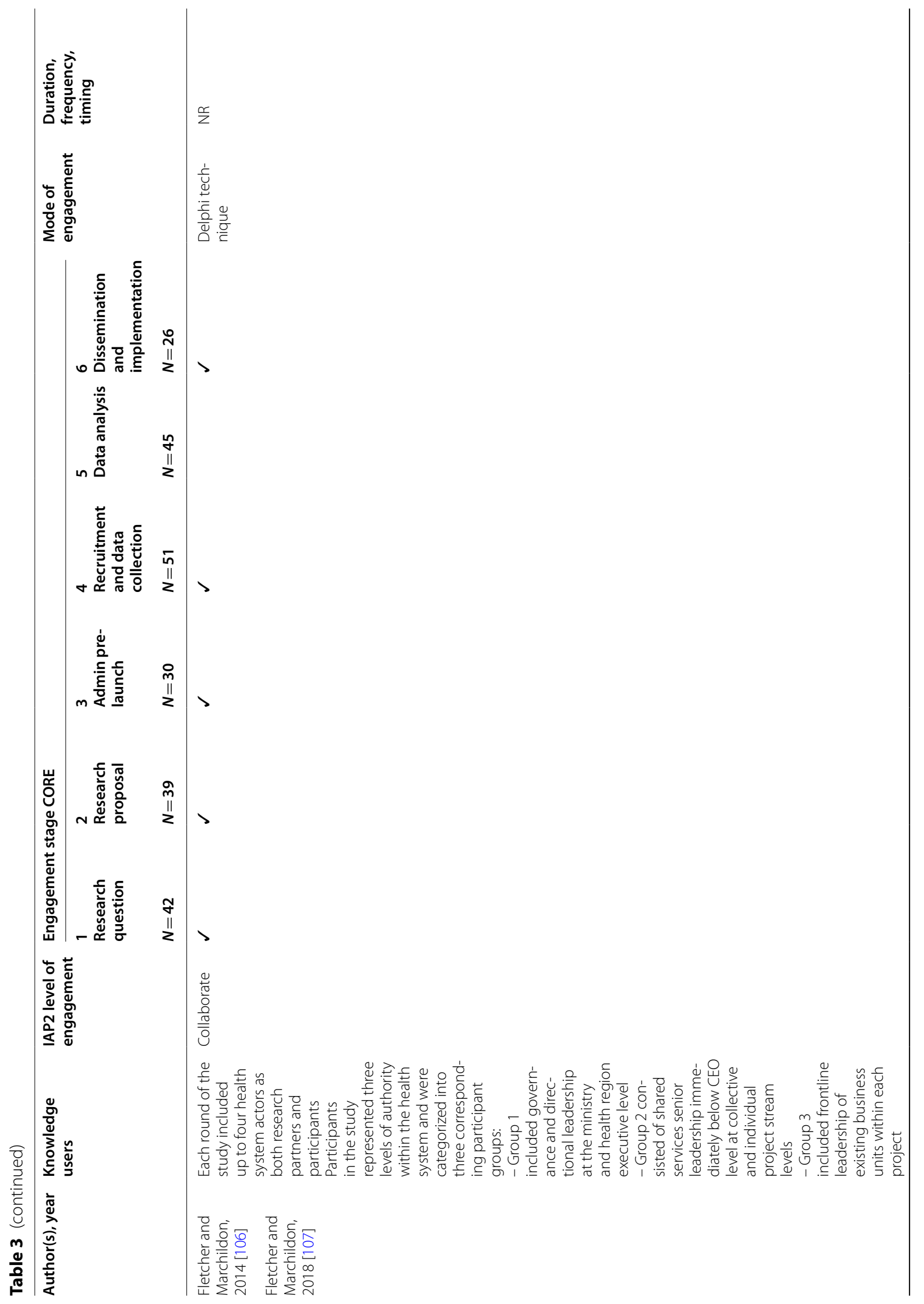




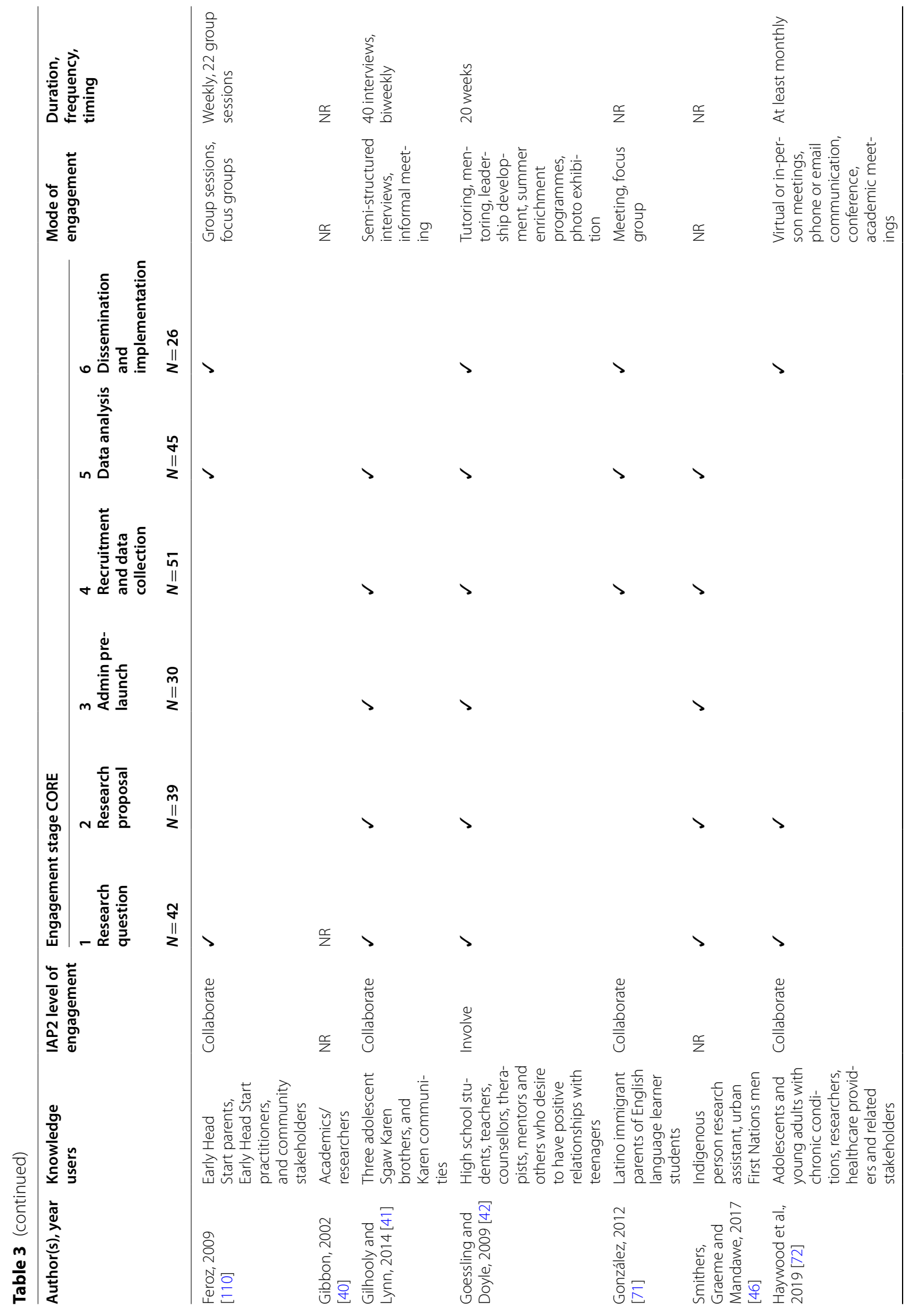




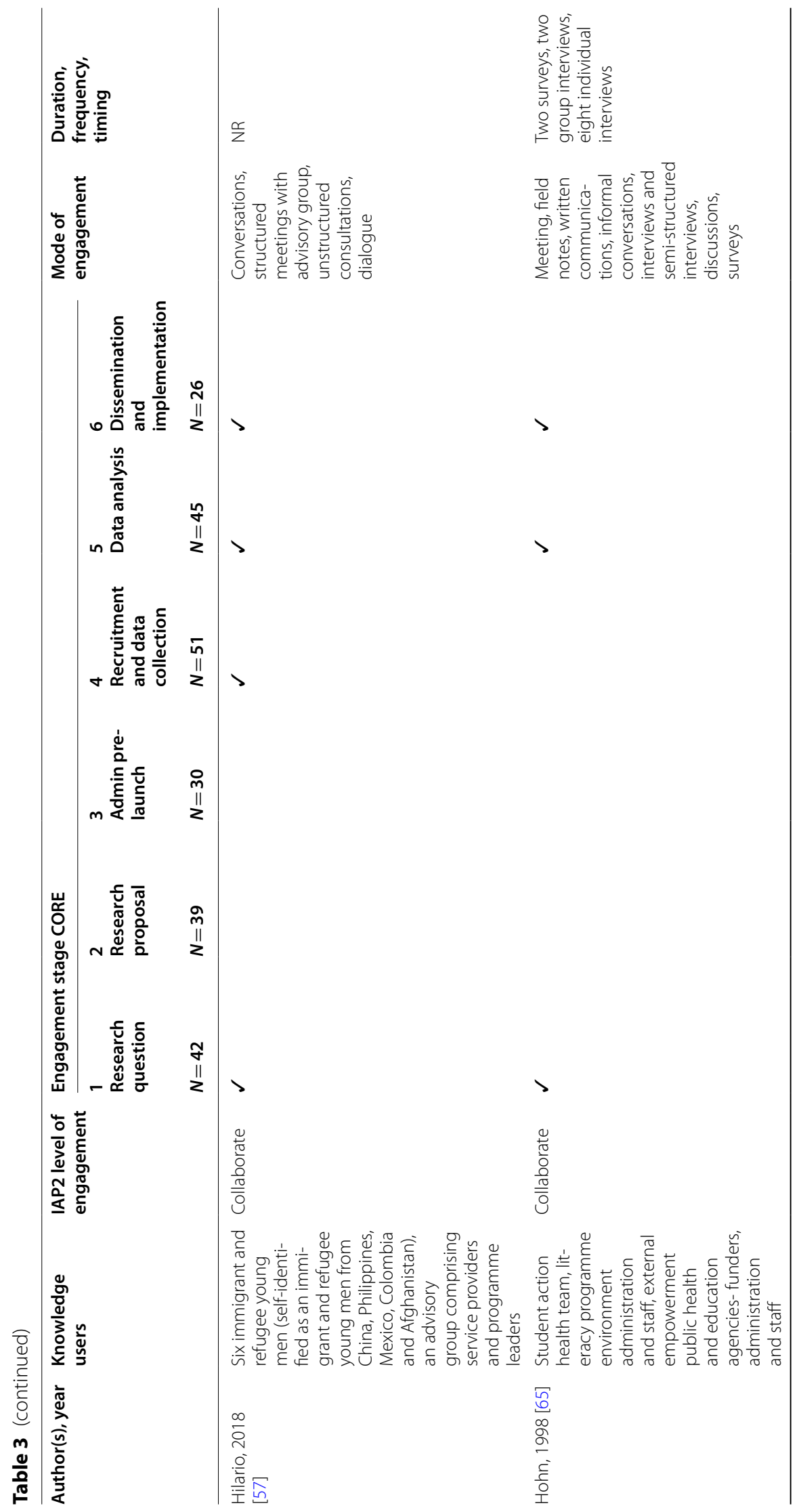




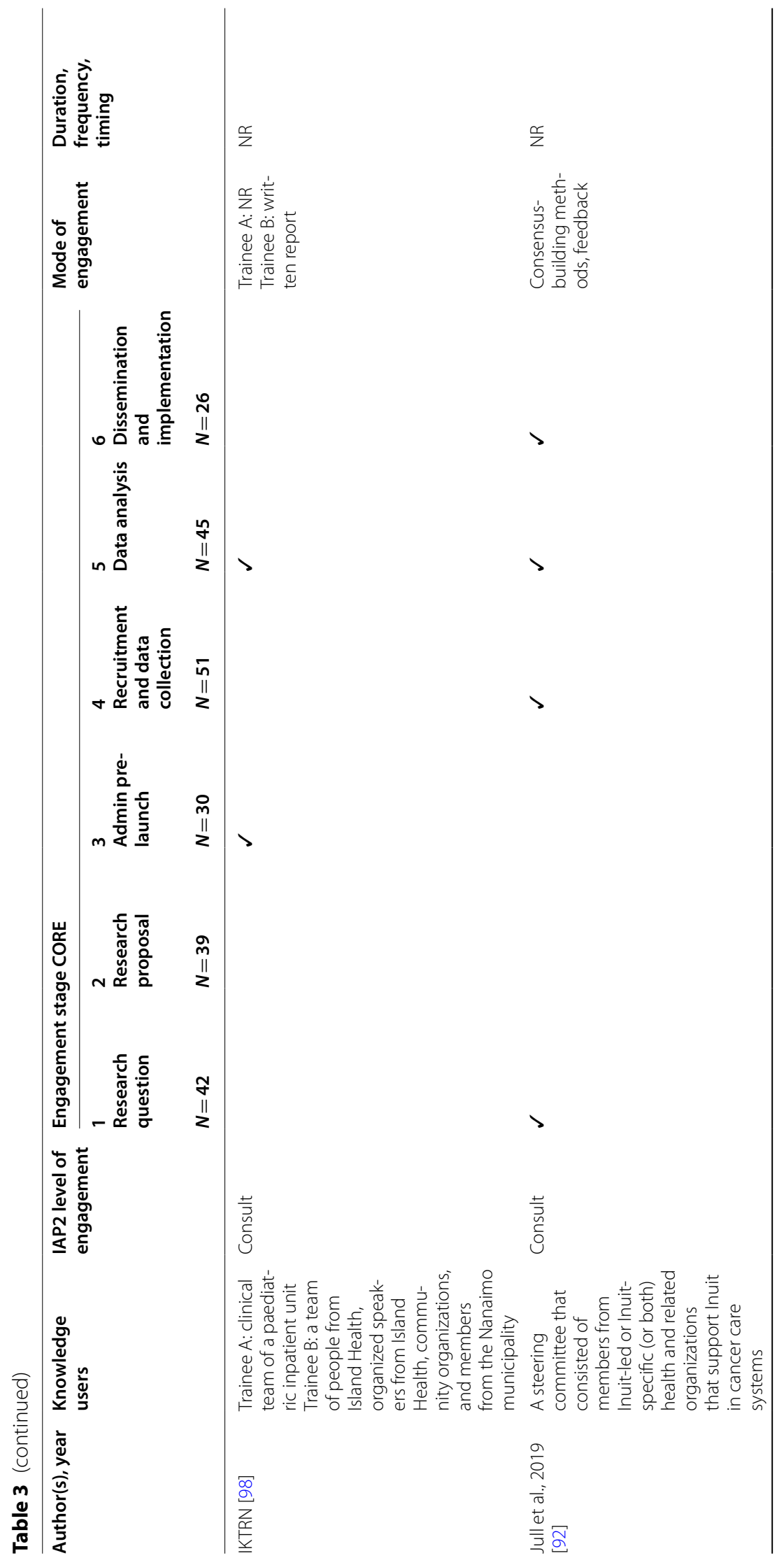




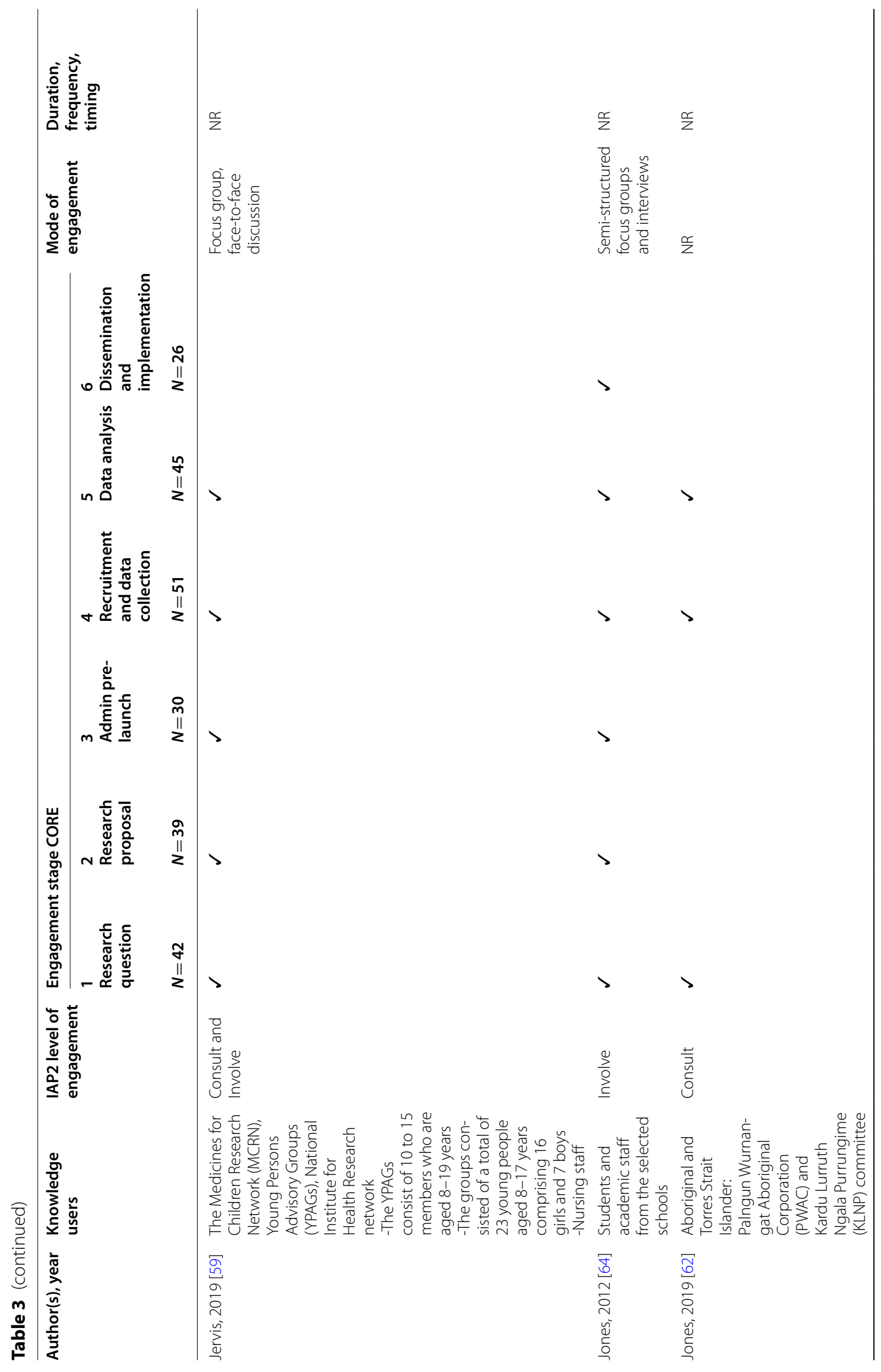




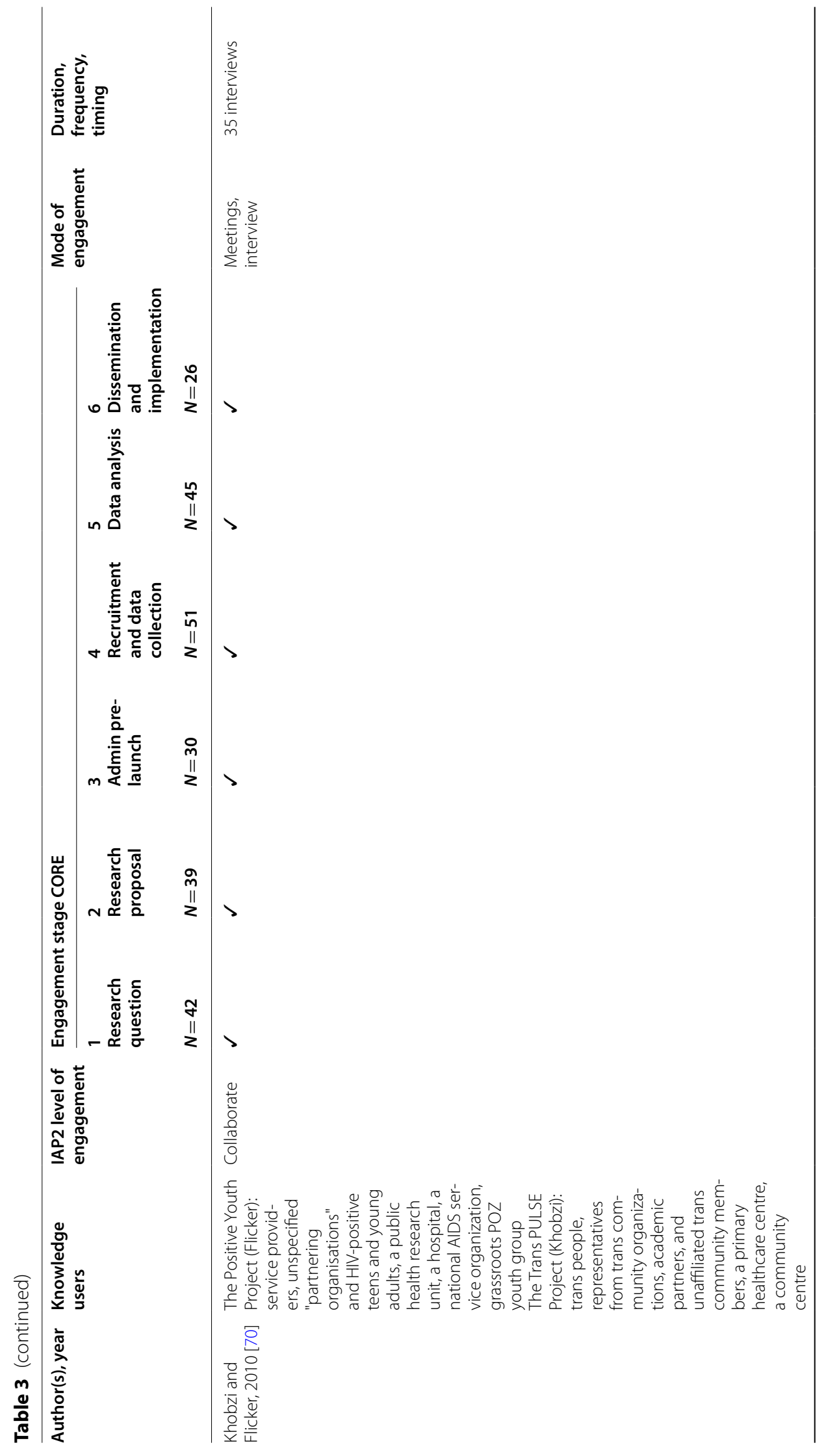




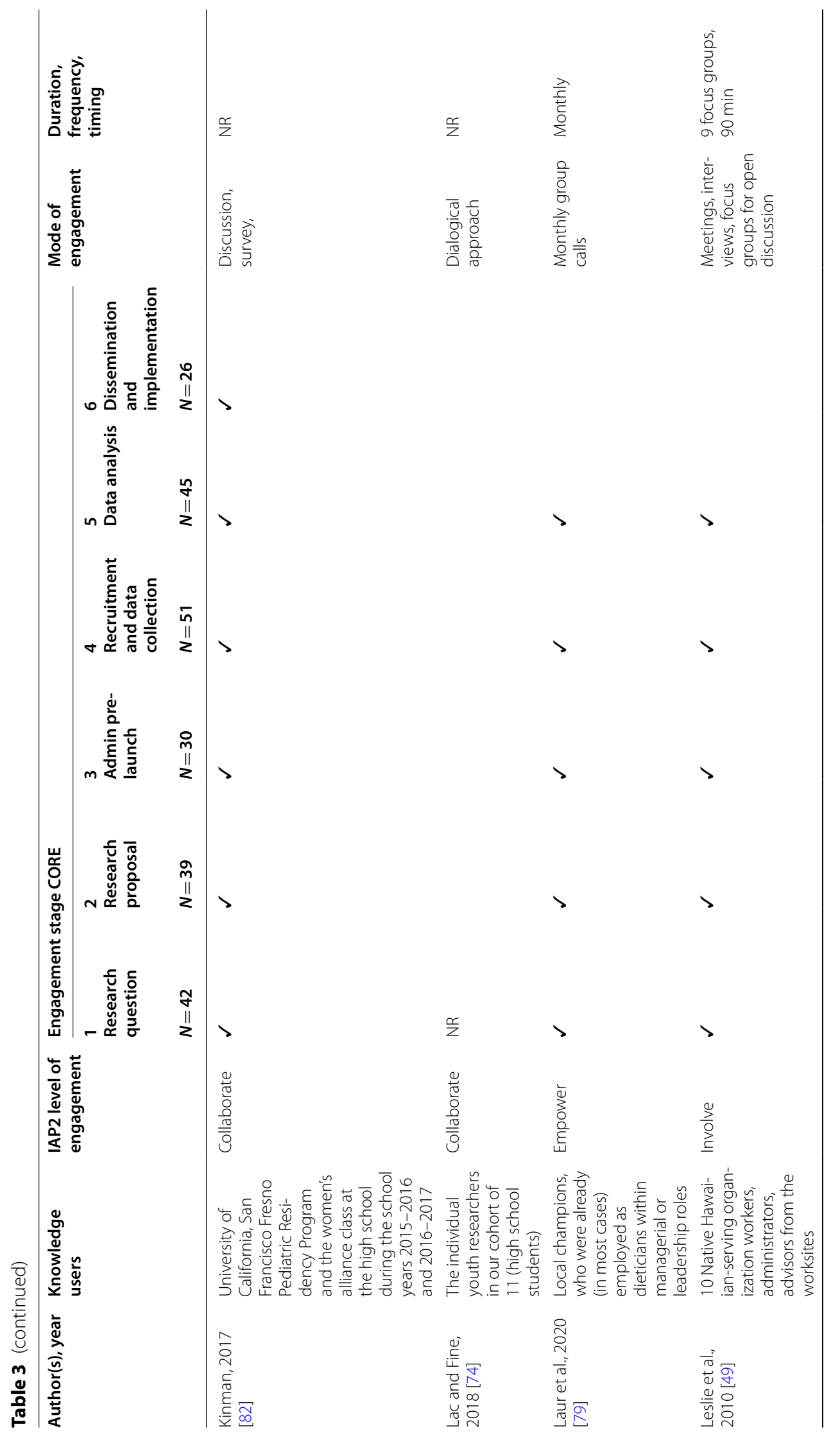




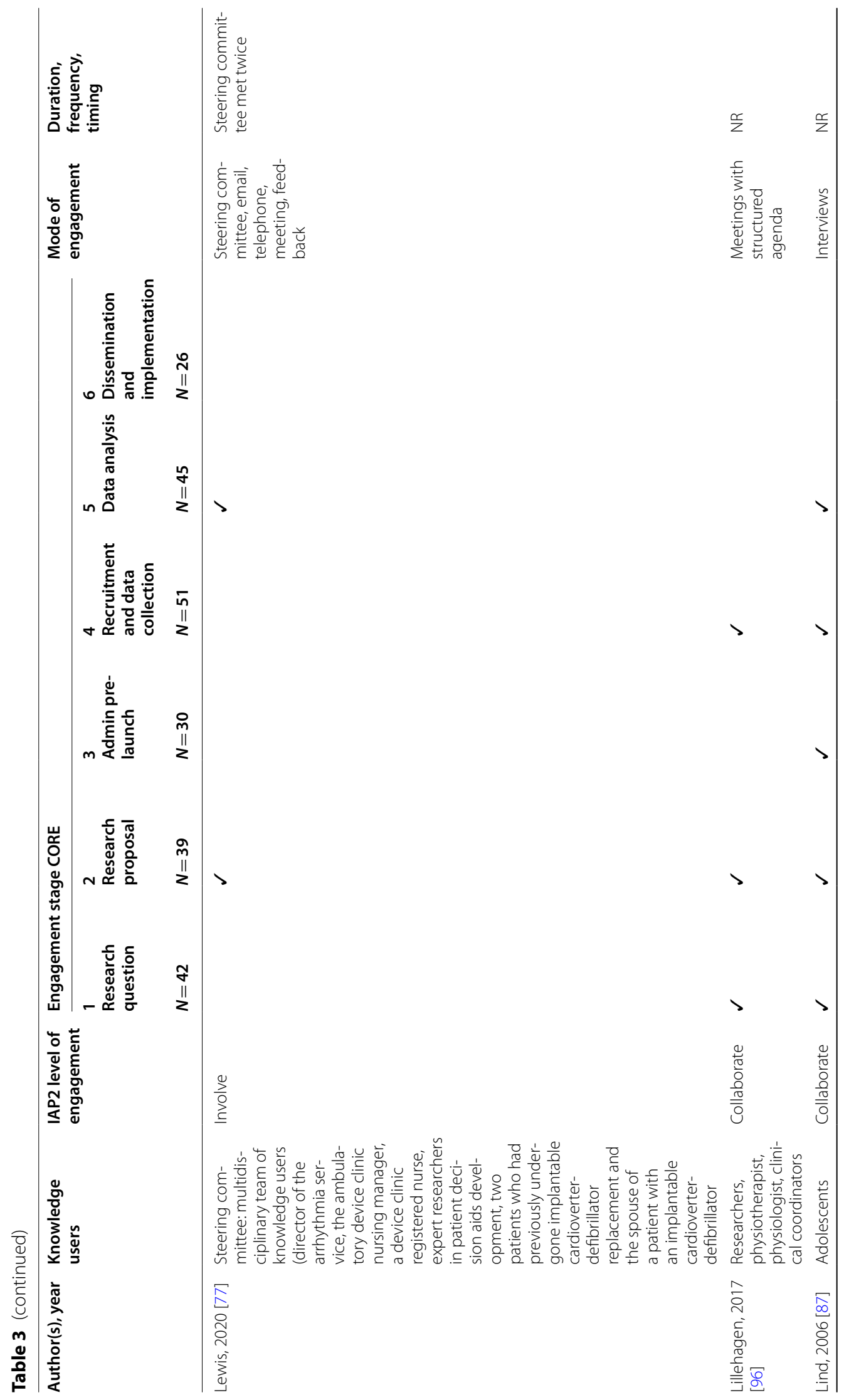




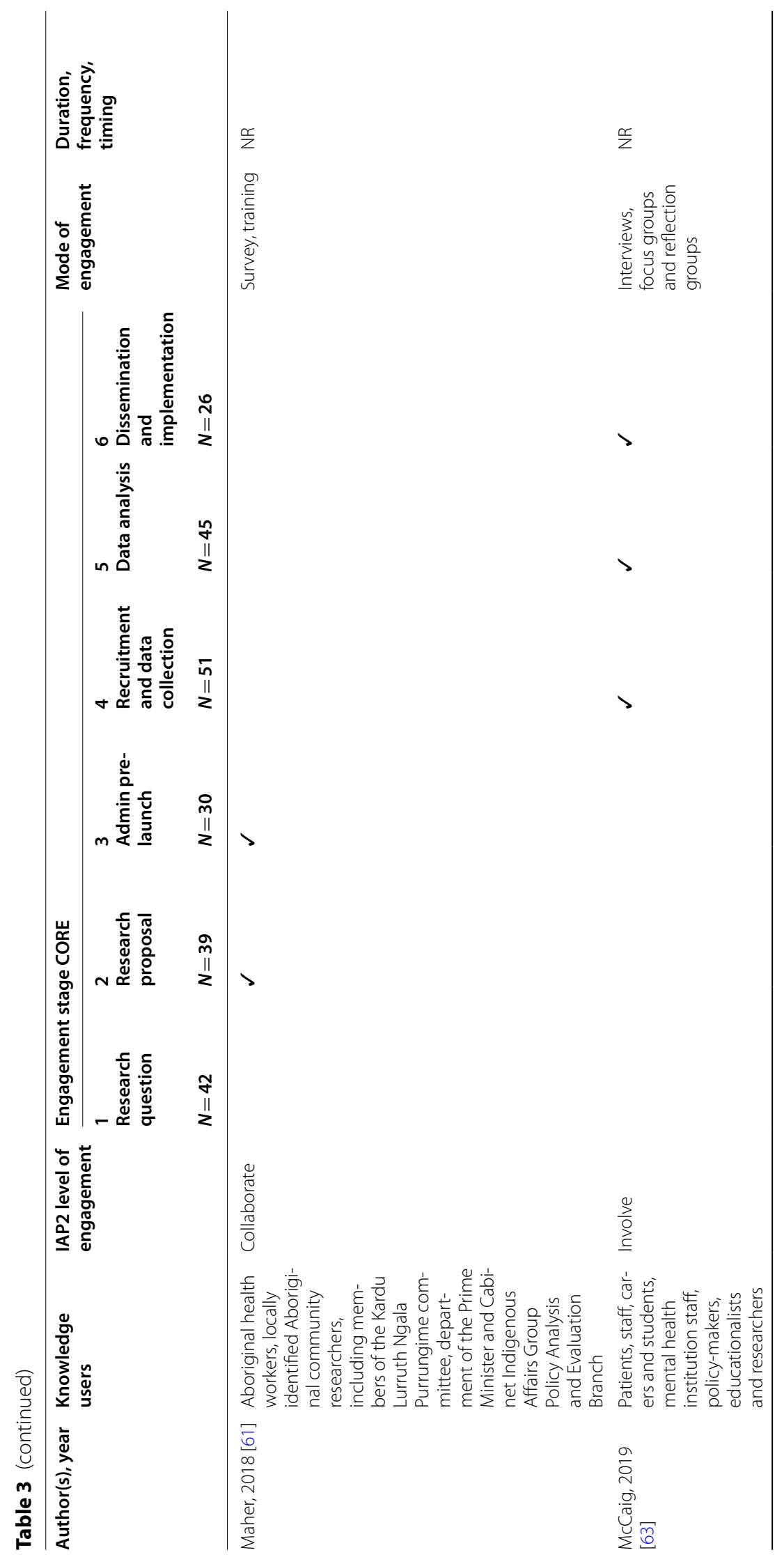




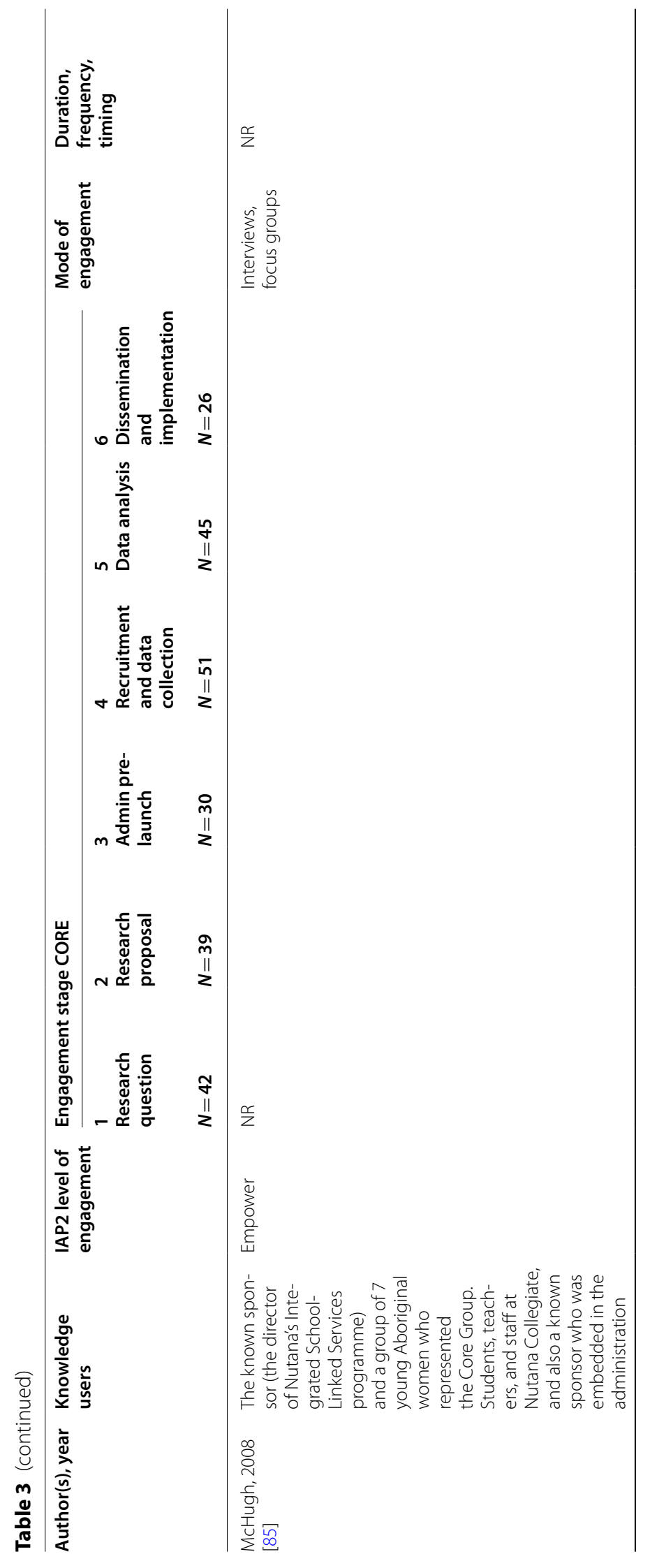




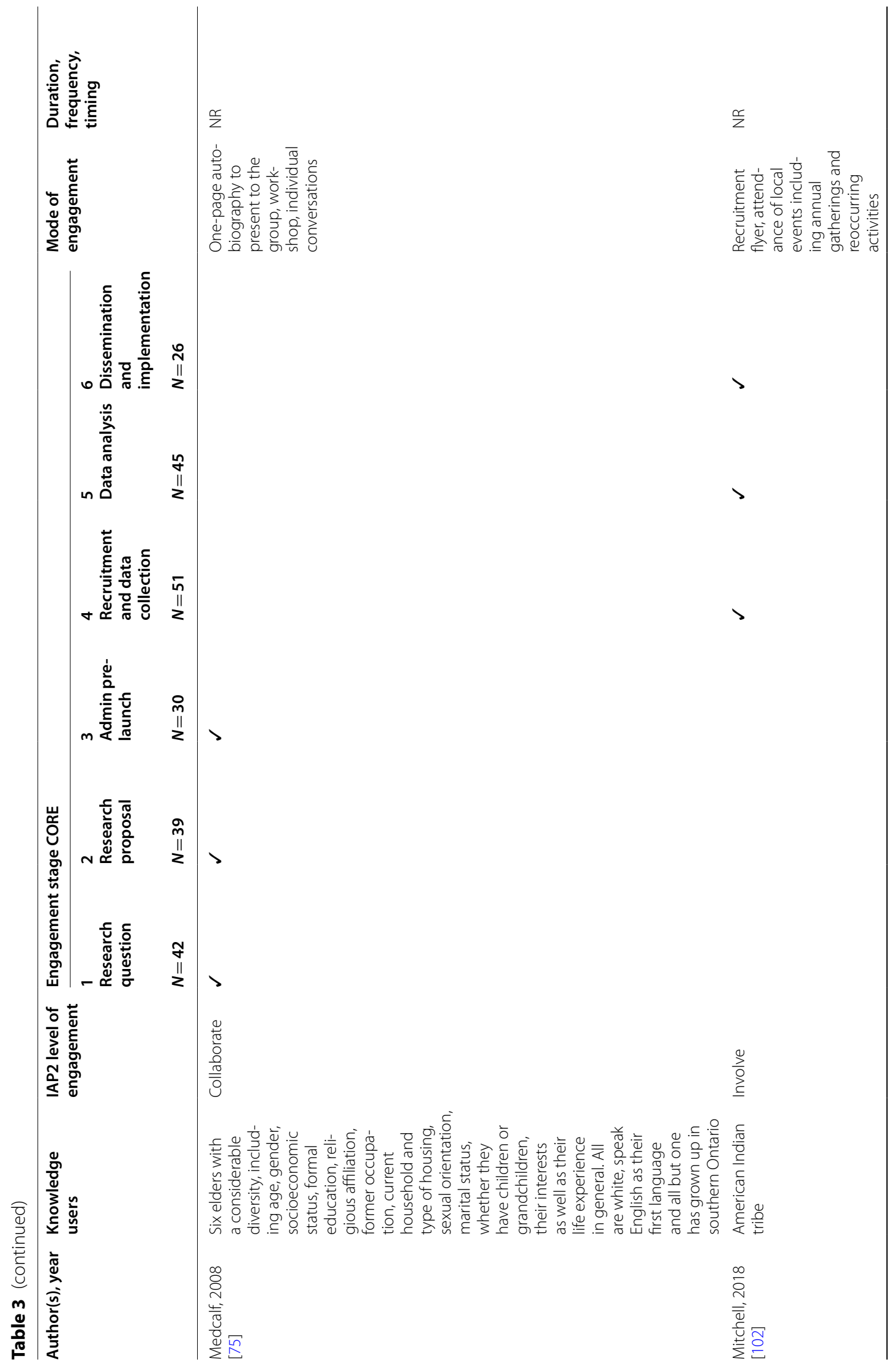




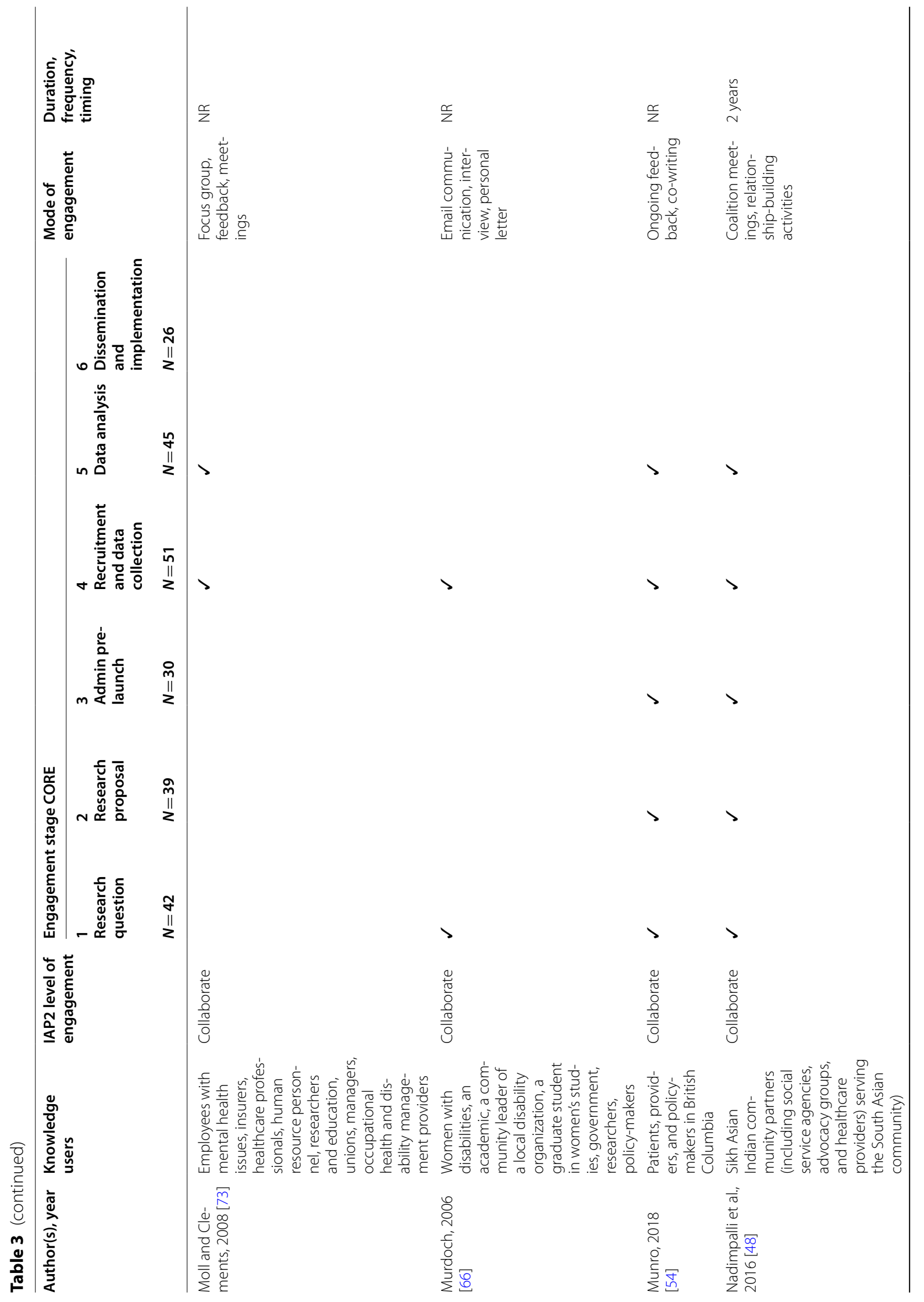




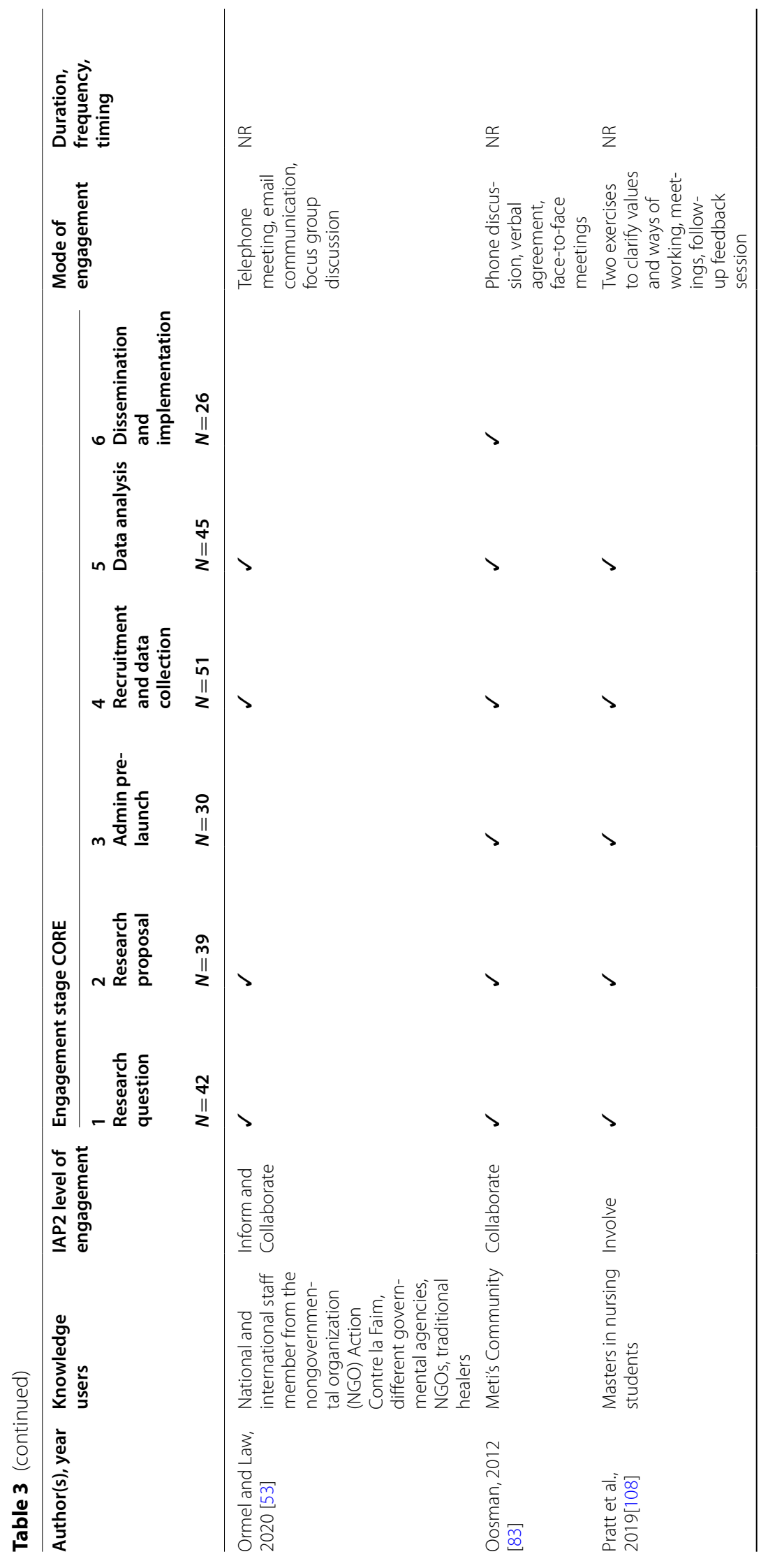




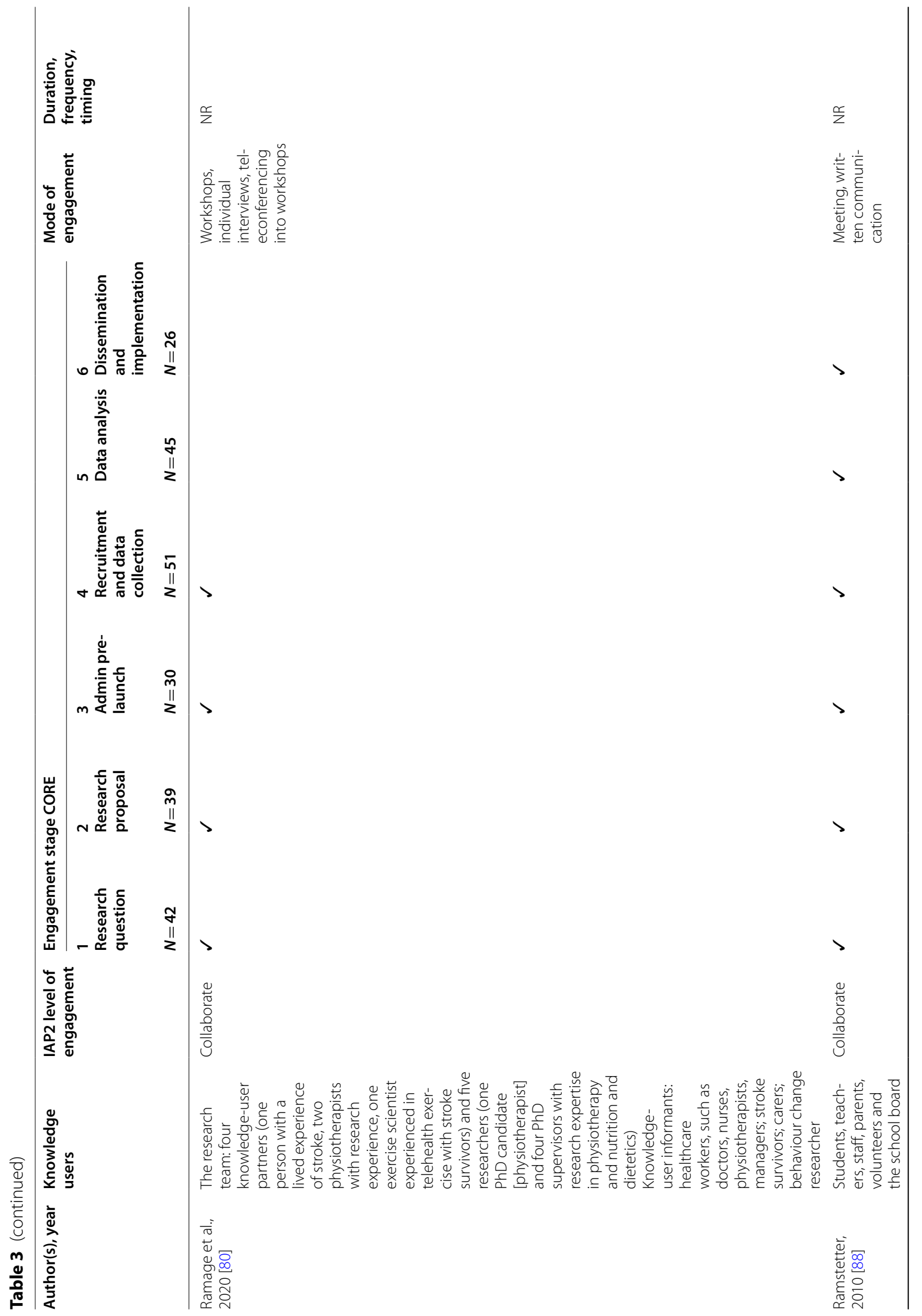




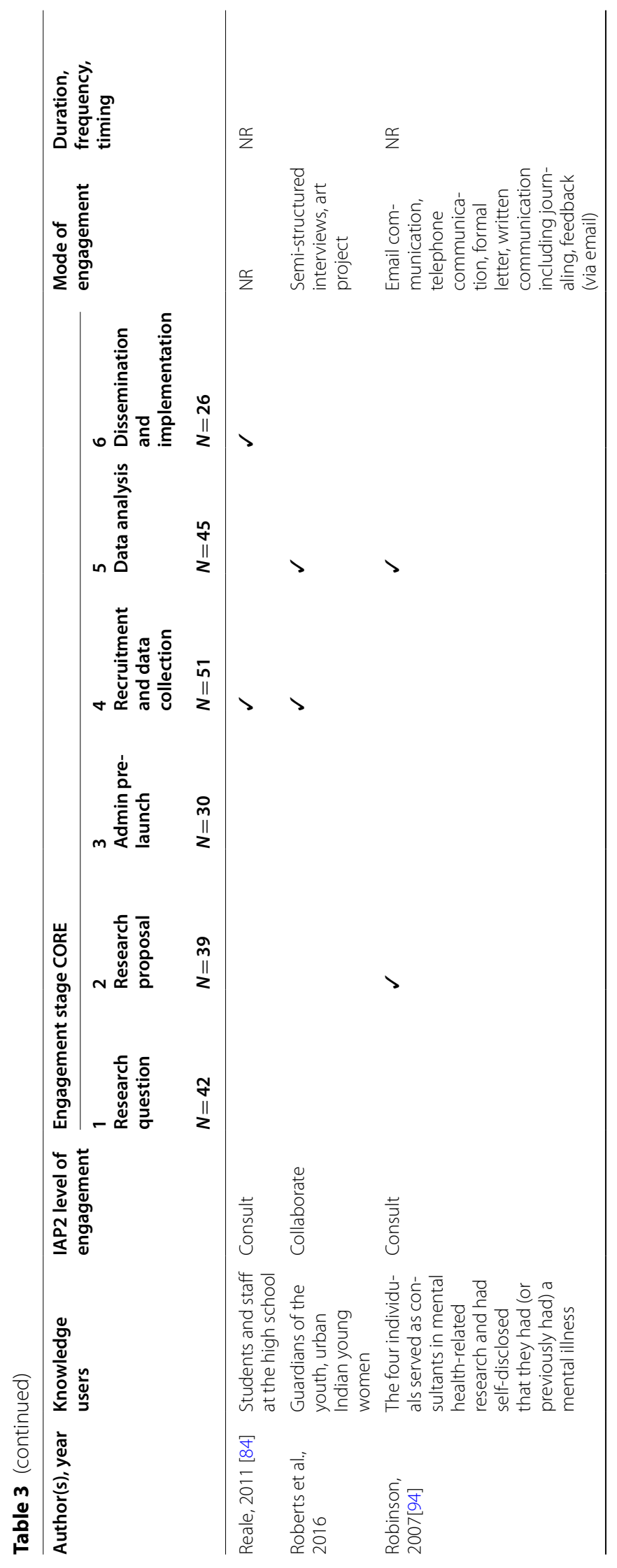




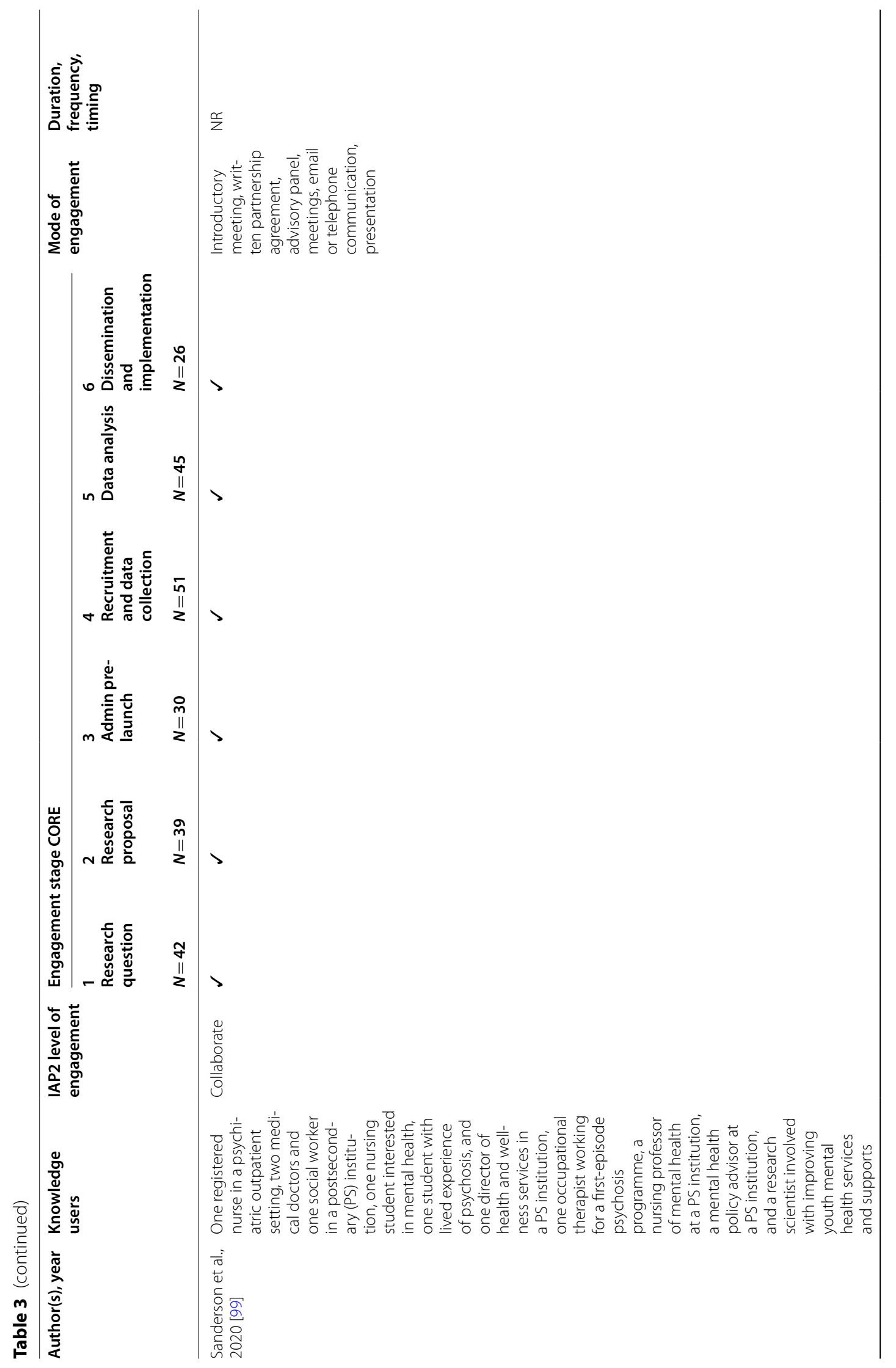




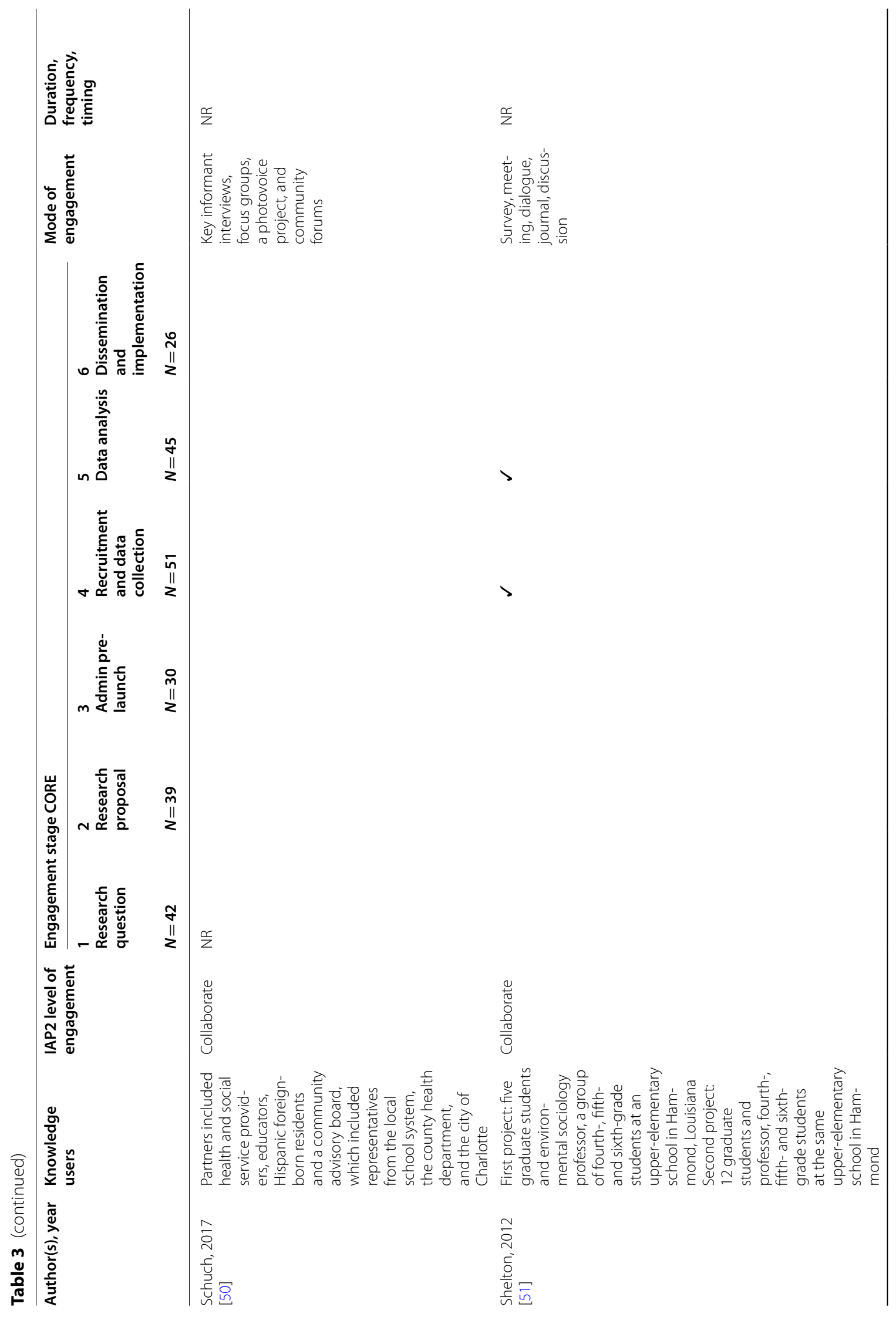




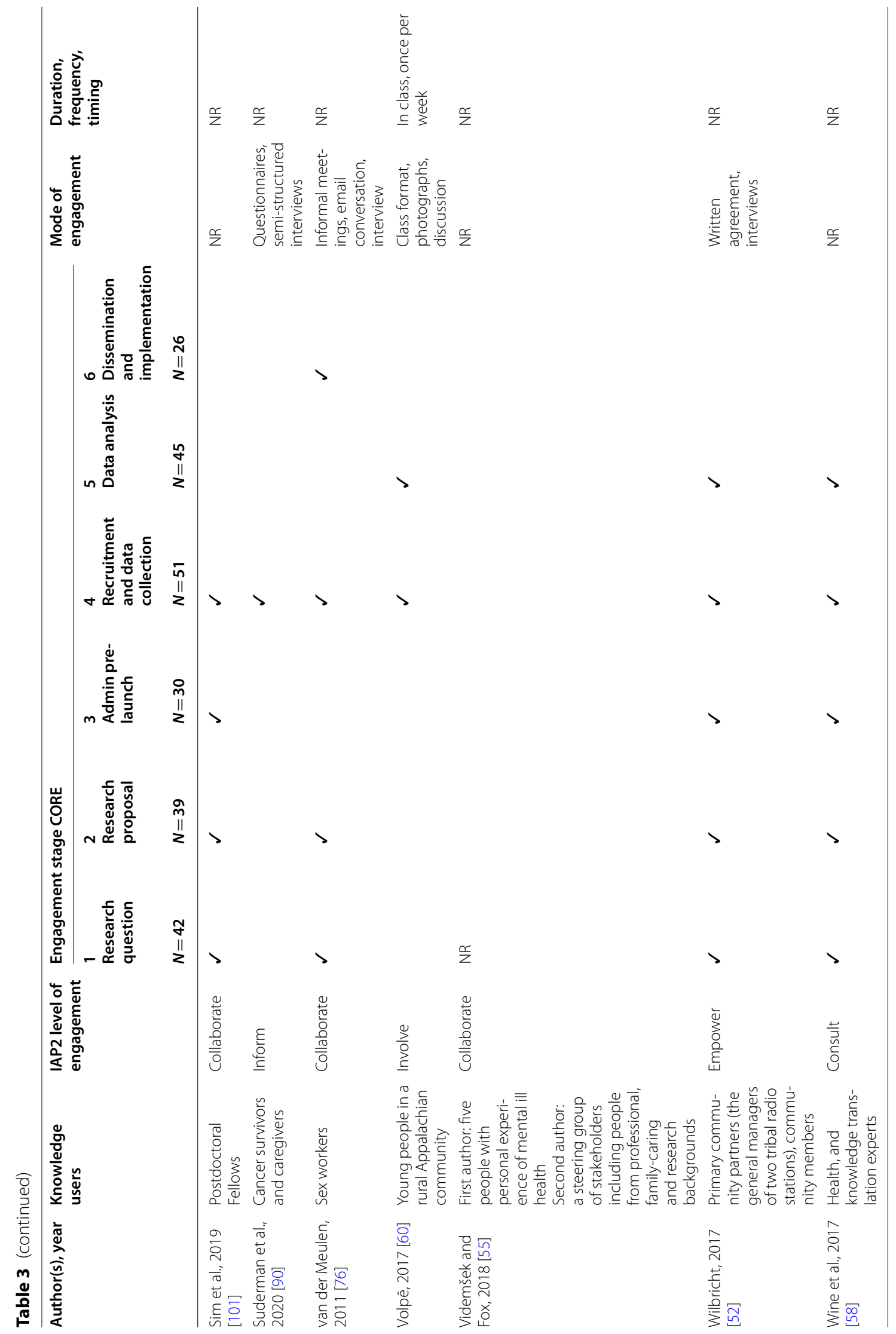


Table 4 Trainee-reported barriers to IKT

\begin{tabular}{|c|c|c|c|}
\hline $\begin{array}{l}\text { COM-B [147] } \\
\text { component }\end{array}$ & $\begin{array}{l}\text { TDF Version } 2 \text { [148] } \\
14 \text { Domains (definition) }\end{array}$ & Themes & Levels \\
\hline \multirow[t]{2}{*}{ Capability } & $\begin{array}{l}\text { Knowledge } \\
\text { (An awareness of the existence of something) }\end{array}$ & \multirow{2}{*}{$\begin{array}{l}\text { Lack of knowledge and skills } \\
\text { Know-how } \\
\text { Procedural techniques (related to research } \\
\text { processes) } \\
\text { Interpersonal skills related to relationships }\end{array}$} & \multirow[t]{2}{*}{ Individual } \\
\hline & $\begin{array}{l}\text { Skills } \\
\text { (An ability or proficiency acquired through practice) }\end{array}$ & & \\
\hline \multirow[t]{2}{*}{ Motivation } & $\begin{array}{l}\text { Social/professional role and identity } \\
\text { (A coherent set of behaviours and displayed } \\
\text { personal qualities of an individual in a social or work } \\
\text { setting) }\end{array}$ & $\begin{array}{l}\text { Trainee as an outsider } \\
\text { Shifting between community, health system, } \\
\text { academia } \\
\text { Trainees do not have insider privilege within any } \\
\text { health organizations } \\
\text { Trainees' non-Native person status doing research } \\
\text { in partnership with Indigenous communities }\end{array}$ & Individual, interpersonal \\
\hline & $\begin{array}{l}\text { Goals } \\
\text { (Mental representations of outcomes or end states } \\
\text { that an individual wants to achieve) }\end{array}$ & $\begin{array}{l}\text { Competing priorities of knowledge users, trainees } \\
\text { and university } \\
\text { Containing scope for thesis project } \\
\text { University guidelines and expectations } \\
\text { Health system priorities }\end{array}$ & Interpersonal, organizational \\
\hline \multirow[t]{2}{*}{ Opportunity } & $\begin{array}{l}\text { Social influences } \\
\text { (Those interpersonal processes that can cause } \\
\text { individuals to change their thoughts, feelings or } \\
\text { behaviours) }\end{array}$ & $\begin{array}{l}\text { Power dynamics } \\
\text { Power/pressure from institutions } \\
\text { Administrative pressure } \\
\text { Intergroup relationships or group dynamics } \\
\text { Connecting, communicating and building rela- } \\
\text { tionship } \\
\text { Push-back and scepticism }\end{array}$ & Interpersonal, organizational \\
\hline & $\begin{array}{l}\text { Environmental context and resources } \\
\text { (Any circumstance of a person's situation or } \\
\text { environment that discourages or encourages the } \\
\text { development of skills and abilities, independence, } \\
\text { social competence and adaptive behaviour) }\end{array}$ & $\begin{array}{l}\text { Lack of funding to support knowledge user par- } \\
\text { ticipation } \\
\text { Barriers to engagement due to physical location/ } \\
\text { distance } \\
\text { Lack of time for trainees } \\
\text { Engagement activities } \\
\text { Trainee's institutional programme } \\
\text { Institutional restrictions } \\
\text { University thesis guidelines } \\
\text { Research ethics board } \\
\text { Health organizations }\end{array}$ & Organizational \\
\hline
\end{tabular}

levels. Further, the three levels demonstrate the complex nature of individual trainees within a broad micro-, meso-, macro-system. Some of the barriers are the direct opposite of facilitators; for example, lack of funding and financial resources are reciprocal barriers and facilitators.

\section{IKT impact and outcomes}

As shown in Table 6, reported IKT impact and outcomes were related to immediate $(n=38)$, intermediate $(n=40)$ and/or long-term $(n=15)$ outcomes of partnership formation. Twenty studies did not report outcomes related to IKT or other research partnerships. See Table 6 for more detail.

\section{Discussion}

This scoping review describes how IKT or other research partnership approaches have been applied in thesis and/ or postdoctoral health research. We identified 74 papers from published and grey literature sources to be included in the review. Overall, study findings provide insights for trainees interested in IKT or other research partnership approaches, and offer guidance on how to apply an IKT approach to their research. Further, the review highlights the important role that academic supervisors, knowledge users, and academic and health system institutions play in providing support and infrastructure to facilitate IKT or other research partnerships in trainee-led health research.

IKT/research partnership principles, strategies and/or tools The majority of studies involved collaboration with knowledge users in the research question development, recruitment and data collection stages of the research process. We used the IAP2 Spectrum [30] as a way to categorize the levels of knowledge user engagement. It is important to note that, as reviewers, we had to make inferences on the level of engagement due to a lack of reporting on IKT and research partnership principles and strategies. We categorized the majority of studies $(n=43)$ in the collaborate stage, which indicates a high level of 
Table 5 Trainee-reported facilitators of IKT

\begin{tabular}{|c|c|c|c|}
\hline COM-B component & $\begin{array}{l}\text { TDF Version } 2 \text { [148] } \\
14 \text { Domains (definition) }\end{array}$ & Themes & Level \\
\hline \multirow[t]{3}{*}{ Capability } & $\begin{array}{l}\text { Knowledge } \\
\text { (An awareness of the existence of something) }\end{array}$ & Education/coursework on research partnerships & Individual \\
\hline & $\begin{array}{l}\text { Skills } \\
\text { (An ability or proficiency acquired through } \\
\text { practice) }\end{array}$ & $\begin{array}{l}\text { Facilitation skills } \\
\text { Use of clear and common language } \\
\text { Trainee's reactivity and problem-solving skills }\end{array}$ & \\
\hline & $\begin{array}{l}\text { Behavioural regulation } \\
\text { (Anything aimed at managing or changing } \\
\text { objectively observed or measured actions) }\end{array}$ & $\begin{array}{l}\text { Trainee's flexibility and reflexivity } \\
\text { Adapting expectations } \\
\text { Project adaptability } \\
\text { Fluidity between knowledge user and aca- } \\
\text { demia } \\
\text { Self-reflection }\end{array}$ & \\
\hline \multirow[t]{2}{*}{ Motivation } & $\begin{array}{l}\text { Social/professional role and identity } \\
\text { (A coherent set of behaviours and displayed } \\
\text { personal qualities of an individual in a social or } \\
\text { work setting) }\end{array}$ & $\begin{array}{l}\text { Trainee as an insider } \\
\text { Pre-existing relationship with knowledge user } \\
\text { Previous experience in the field (e.g., clinical } \\
\text { background) } \\
\text { Ongoing efforts to maintain meaningful } \\
\text { relationship } \\
\text { Trainees view themselves as a "facilitator" }\end{array}$ & Individual, interpersonal \\
\hline & $\begin{array}{l}\text { Goals } \\
\text { (Mental representations of outcomes or end } \\
\text { states that an individual wants to achieve) }\end{array}$ & $\begin{array}{l}\text { Setting common goals early when doing } \\
\text { research and setting goals in knowledge user } \\
\text { meetings } \\
\text { Clear plan } \\
\text { Memorandum of understanding (MOU) } \\
\text { Planned agendas }\end{array}$ & \\
\hline \multirow[t]{2}{*}{ Opportunity } & $\begin{array}{l}\text { Environmental context and resources } \\
\text { (Any circumstance of a person's situation or } \\
\text { environment that discourages or encour- } \\
\text { ages the development of skills and abilities, } \\
\text { independence, social competence and adaptive } \\
\text { behaviour) }\end{array}$ & $\begin{array}{l}\text { Financial resources } \\
\text { Academic resources } \\
\text { Time/scheduling to support partnership } \\
\text { Person and environment interaction } \\
\text { Straddle both environments (i.e., community, } \\
\text { institution, hospital) }\end{array}$ & Interpersonal, organizational \\
\hline & $\begin{array}{l}\text { Social influences } \\
\text { (Those interpersonal processes that can cause } \\
\text { individuals to change their thoughts, feelings or } \\
\text { behaviours) }\end{array}$ & $\begin{array}{l}\text { Trusting relationship and creating safe place for } \\
\text { partnership } \\
\text { Team transparency } \\
\text { Respect for diverse perspective } \\
\text { Existing relationship and/or partnership } \\
\text { Supportive group dynamics } \\
\text { Knowledge users who support the research } \\
\text { Partners'aligned interest with the research } \\
\text { IKT expert support } \\
\text { Supervisors and committee members }\end{array}$ & Interpersonal, organizational \\
\hline
\end{tabular}

partnership in the decision-making process. This is not surprising, as IKT and research partnerships are rooted in deliberate partnership and shared decision-making throughout the research partnership from start to finish [112]. There are distinct differences between research partnerships that empower partners to be active participants in the shared decision-making process and lesser levels of engagement, such as communication, information-sharing and consultation [113]. The included papers described the former, where trainees made deliberate efforts to support research collaboration with knowledge users and described this partnership in detail. While the IAP2 Spectrum was a useful framework for categorizing engagement, its origins are in broad public participation [111], and it does provide a comprehensive representation of the types of knowledge users involved in health research (i.e., patient, caregivers, healthcare providers, health system leadership and policy). Efforts are needed to develop a clearer set of IKT principles and strategies for knowledge user engagement in the health context.

\section{Barriers and facilitators to using IKT or other research partnership approaches in trainee-led health research} This review illustrates the intersecting barriers and facilitators for IKT and research partnership approaches at the individual, interpersonal and organizational levels (Fig. 2). Many of the reported facilitators were reciprocal to the barriers and have the potential to support IKT or research partnerships, including partnership skill 


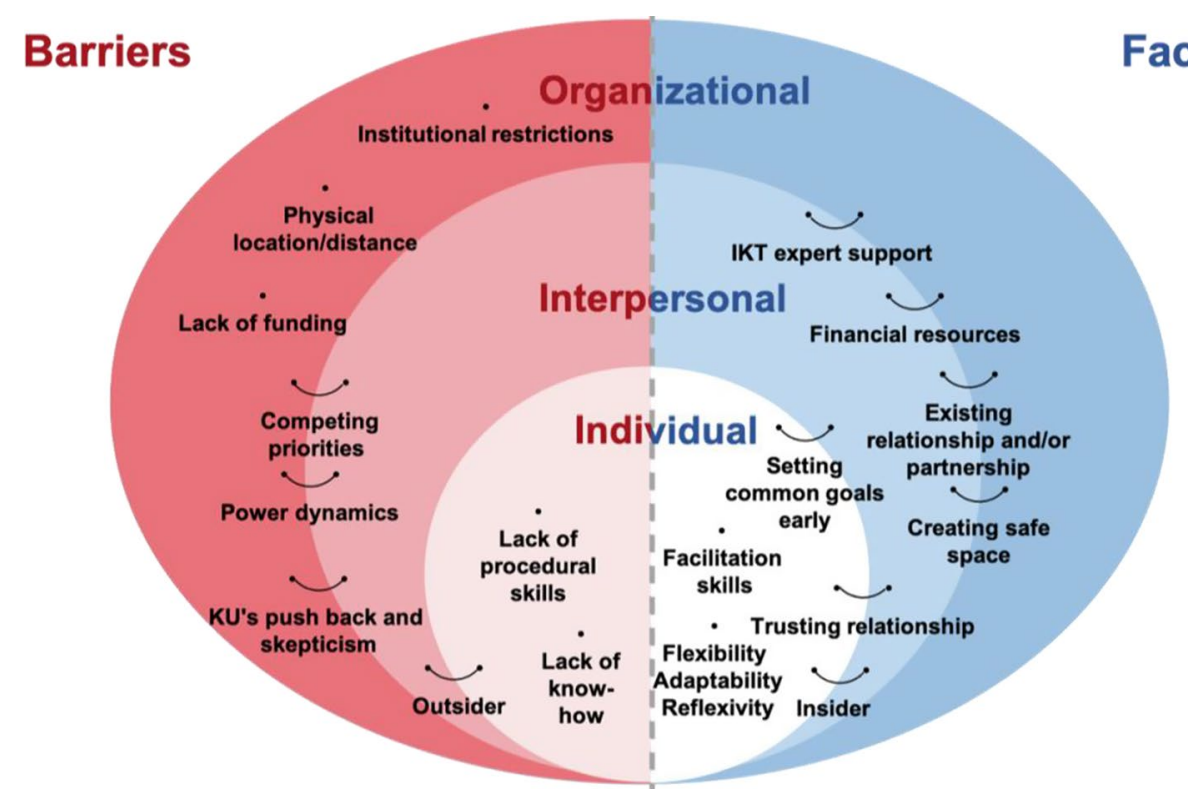

Fig. 2 Barriers and facilitators to IKT/research partnerships in trainee-led research

development, co-creation of common goals and leveraging research programme partnerships. We used the COM-B model of behaviour [33] to categorize reported barriers and facilitators related to trainees' capability, opportunity and motivation for using an IKT or research partnership approach.

\section{Capability}

Our review identified several capability-related barriers and facilitators at the individual trainee level for engaging in IKT research, including IKT knowledge and skills, and flexibility in the research approach. These findings align with recent research highlighting the lack of researcher preparation in research partnership approaches [11, 114]. Building on this known gap in the literature, our review offers a clearer understanding of what types of knowledge and skills are needed to support researcher preparation for collaborative health research, including the development of facilitation skills. Facilitation is defined as "the process of enabling (making easier) the implementation of evidence into practice" [115]. It supports a purposeful two-way process of change that focuses on building trusting relationships and establishing common goals between the facilitator and those engaged in making the change $[116,117]$. More formal training efforts are needed to support facilitation skill development for health research trainees. Dogherty and colleagues developed a taxonomy of 53 facilitation strategies, ranging from providing assistance with certain tasks, to a more holistic process that empowers change in individuals' attitudes and ways of thinking and working. This taxonomy may be a helpful starting point to develop trainees' skills as facilitators in the research process, which to date has not been a primary focus in traditional academic programmes.

Previous research has identified core competencies that trainees need for applied health research and knowledge translation [118, 119]. A baseline self-assessment on these competencies may be helpful for trainees interested in developing their IKT or other research partnership skills [120]. Further, several training programmes exist to provide trainees with experiential learning opportunities in IKT or other research partnerships. For example, the Canadian Institutes of Health Research (CIHR) Health System Impact (HSI) Fellowship was designed to modernize doctoral and postdoctoral training to better equip researchers with the professional and research skills needed to address complex health system challenges [121]. HSI doctoral and postdoctoral research fellows are embedded in health system organizations to develop Canadian Health Services and Policy Research Alliance's 9 enriched core competencies, understand the intricacies of health system delivery, and partner with members of the health system to support relevant research efforts [121]. Similarly, in the United States, AcademyHealth developed the Delivery System Science Fellowship to provide experiential learning and professional development opportunities for postdoctoral trainees [122]. These types of training programmes offer formalized experiences focused on development of professional skills not currently emphasized in health 
Table 6 Reported outcomes

\begin{tabular}{|c|c|c|c|}
\hline Outcomes & Frequency $(N)$ & References & Examples from included papers \\
\hline $\begin{array}{l}\text { Immediate outcomes of partnership forma- } \\
\text { tion }\end{array}$ & Total $=38$ & & \\
\hline $\begin{array}{l}\text { Value for different perspectives/broadened } \\
\text { perspective }\end{array}$ & $N=13$ & $\begin{array}{l}{[37,38,46,57,61,75,76,78,80,84,96,97,} \\
106]\end{array}$ & $\begin{array}{l}\text { Bringing in diverse perspectives from differ- } \\
\text { ent stakeholder groups }\end{array}$ \\
\hline $\begin{array}{l}\text { Mutual understanding of language, work } \\
\text { style, needs and constraints }\end{array}$ & $N=12$ & $\begin{array}{l}{[46,47,54,62,74,77,79,81,88,94,97,} \\
103]\end{array}$ & $\begin{array}{l}\text { Inclusion of strategies to support a use of } \\
\text { common language during workshops }\end{array}$ \\
\hline Appreciation for collaborative process & $N=8$ & {$[38,42,47,48,50,68,69,105]$} & $\begin{array}{l}\text { Trainees reported that they experienced the } \\
\text { value of collaborations }\end{array}$ \\
\hline $\begin{array}{l}\text { Capacity developed by researchers and } \\
\text { decision-makers }\end{array}$ & $N=5$ & {$[37,69,72,98,109]$} & $\begin{array}{l}\text { Trainees and/or partners gained experience } \\
\text { (e.g., public speaking, professional network- } \\
\text { ing and writing) }\end{array}$ \\
\hline $\begin{array}{l}\text { Intermediate outcomes of partnership } \\
\text { formation }\end{array}$ & Total $=40$ & & \\
\hline Enhanced relevance of research & $N=18$ & $\begin{array}{l}{[37,47,48,63,72,73,76,77,80,84,90,} \\
97-101,103,106]\end{array}$ & $\begin{array}{l}\text { Trainees reported improved relevance of } \\
\text { the research being conducted and/or its } \\
\text { findings }\end{array}$ \\
\hline Awareness and acceptance of research & $N=11$ & {$[42,45,52,71,76-80,85,95]$} & $\begin{array}{l}\text { Gaining approval or "buy-in" of research from } \\
\text { partners }\end{array}$ \\
\hline Conduct of research & $N=5$ & {$[38,46,58,91,109]$} & $\begin{array}{l}\text { Trainees reported that partnership } \\
\text { approaches allowed for an improved } \\
\text { research process }\end{array}$ \\
\hline Identification of research questions & $N=3$ & {$[39,94,96]$} & Developing research questions together \\
\hline Research output & $N=3$ & {$[50,70,72]$} & $\begin{array}{l}\text { Co-authorship publication with knowledge } \\
\text { users }\end{array}$ \\
\hline $\begin{array}{l}\text { Long-term outcomes of partnership forma- } \\
\text { tion }\end{array}$ & Total $=15$ & & \\
\hline Use of research in practice/policy & $N=9$ & {$[67,76,80,82,83,95,101,106,110]$} & $\begin{array}{l}\text { Development of relevant practice change(s) } \\
\text { in hospital or community }\end{array}$ \\
\hline Scale-up/spread of research & $N=5$ & {$[37,38,41,88,100]$} & Research is spread to new areas \\
\hline System/health service outcomes & $N=1$ & {$[77]$} & $\begin{array}{l}\text { Changes in clinic processes and increased } \\
\text { clinicians self-efficacy }\end{array}$ \\
\hline
\end{tabular}

Not reported $N=20$

services graduate training. Trainees may wish to consider these types of formalized training programmes to further their IKT skills development and better support the use of a research partnership approach in their graduate or postdoctoral research.

\section{Opportunity and motivation}

Successful research partnerships require more than individual trainees having the right skills and willingness to engage with knowledge users. The majority of barriers and facilitators identified in this review were categorized in the interpersonal and organizational levels, specific to intersecting opportunity and motivation determinants that either support or hinder research partnerships for trainees.

Trainees reported that their status as an insider or outsider to the organization/community was a key facilitator or barrier for building partnerships. This is consistent with Dwyer and Buckle's [123] previous work; having an insider membership typically gives an advantage to researchers, as it creates a sense of trust and openness from the participants. However, researchers are never completely insiders or outsiders, and their status does not make for a better or worse researcher [123-125]. Dwyer and Buckle [123] challenge the dichotomous insider and outsider identity of researchers and propose that "space between" is critical. In this "space between," [123], researcher's positionality is complex and fluid in nature [126] and can impact the research topic, epistemology, ontology and methodology [127]. Therefore, when trainees engage in IKT, it is more important that they practice self-reflexivity to understand their positionality in the study rather than focus on whether they are insiders or outsiders. Moreover, this is consistent with our findings on trainees reporting reflexivity as a facilitator for engaging in IKT research. We encourage trainees to reflect on the commonalities and differences they share with their research partners and how their positionality in the "space between" might affect research relationships. From there, trainees may have a better sense of how to 
navigate relationship-building with different knowledge user groups.

Academic supervisors play an important role in supporting trainees to navigate the "space between" and develop effective research partnerships with knowledge users. Our findings reinforce previous research on leveraging pre-existing research relationships to support IKT $[18,128]$ and highlight the value of research programme partnerships to facilitate trainee IKT research. Research programme partnerships and longer-term relationships, as opposed to one-off project partnerships, offer time and space for clear articulation of expectations, which allows for effective collaboration and mutual gain [129]. If research programme partnerships exist, it is easier for trainees to align their project within their supervisors' larger research programme, which includes clearly developed practice linkages and existing research partnership supports [128]. Further, research programme partnerships ensure continuity of relationships between academia and the health system; when a trainee finishes their training and moves on to their next career stage, the supervisor can maintain the research partnership with the knowledge user. There may also be instances where trainees bring their own knowledge user partnerships into their academic training. For example, several papers described an existing role that trainees had within a community or organization, in which they used their partnerships to build a research study $[76,88]$. In this scenario, supervisors should respect this pre-existing relationship and offer support on the academic research process to further develop the existing relationship into an effective research partnership.

Our findings also highlight how interpersonal influences can help and/or hinder the research partnership. The interpersonal and group dynamic barriers and facilitators to research partnerships illustrate the inherent relationship focus of IKT. Previous reviews of IKT-related literature have highlighted similar relationship-focused barriers and enablers to partnership research $[4,5,17$, 130]. Power dynamics are often at the core of research partnerships [131]. Several included studies highlight the influence of power hierarchies on the trainee experience with IKT, including pressure from both the academic and health institution to meet certain deliverables and timelines. This is particularly relevant for trainees who are already challenged with power hierarchies within the academy and may be entering into additional power differentials with knowledge users. Establishing mutually respectful relationships requires trust-building and being trustworthy to promote power-sharing and co-create knowledge [130]. Humility is an emerging area of interest in the field of IKT for developing meaningful and trustworthy research partnerships [132]. Humility stresses the need for self-assessment of one's intellectual strengths and limitations, but also an appreciation of the contributions of others [133, 134]. Key strategies for practicing humility include clarity of thinking, open-mindedness, a commitment to mutual learning and ensuring that researchers do not bring a view of themselves as superior to the research team [132]. It is important for trainees to practice humility during research partnerships by acknowledging their positionality and taking the time to learn about the context and culture of an organization or community [132, 135]. These efforts will support collaboration, mutual learning and responsiveness among researchers, communities and health organizations.

Several organizational barriers and facilitators influence trainees' opportunity and motivation for engaging in IKT or other research partnerships. Included papers reported a number of competing priorities among trainees (e.g., thesis/project completion), knowledge users (e.g., patient care, service delivery, resource use) and university institutions (e.g., timely thesis completion, resource use). Similarly, previous IKT research has illustrated how competing priorities can hinder successful research partnerships $[4,27,136]$. However, this review details specific challenges that trainees encounter with IKT. Individual trainees may have the motivation to engage in research partnerships, but there is often a lack of structures and resources in place to support the IKT process (e.g., funding to support knowledge user engagement). Our findings build on previous IKT recommendations including co-creating value-driven work with a shared purpose, and thereby fostering mutual gain [129, 137]. Further, institutional resources (e.g., funding) and policies are needed to support research partnership approaches for trainees, including flexibility in thesis guidelines, memoranda of understanding between academic and health system institutions, and tangible resources (i.e.,guidelines, worksheets) to support co-creation of common goals.

\section{IKT or other research partnership outcomes}

IKT and other research partnership approaches suggest that active engagement of knowledge users throughout the research process increases the use of research in practice and policy [2,4]. Despite the positive intent of IKT and research partnerships, there has been limited empirical evidence of the effects of IKT on evidence use to inform policy and practice [4]. Building on Gagliardi and colleagues' scoping review on IKT [4], we organized our outcome findings into three categories of partnership formation. Most papers reported on intermediate outcomes of partnership formation, such as enhanced relevance of research $(n=18)$, and partnership formation outcomes, such as valuing different perspectives $(n=13)$. 
However, only nine studies reported the use of research in practice/policy as an outcome, which is the primary goal of IKT. Further, over a quarter $(n=20 / 72)$ did not report outcomes at all. These findings highlight the lack of studies evaluating the impact of the IKT beyond the partnership formation and relevance of research. Efforts are needed to advance the science by moving the field beyond partnership formation studies and understanding the impact of IKT on conceptual, symbolic and instrumental use.

Our findings align with recent calls to advance IKT evaluation, including Kreindler's [138] work on using a realist evaluation approach to examine how IKT influences the tangible use of evidence in decision-making related to practice and policy. Realist evaluation investigates "what is it about an intervention that works, for whom, and under what conditions' [139] and is a valuable approach for understand the complexity and nuances of IKT partnerships. Quantitative research methods are also warranted in IKT research, including the application of valid and reliable measurement tools of knowledge user engagement. Several tools exist for patient and public engagement in research that may be useful in examining broader stakeholder engagement (i.e., patients, public, healthcare providers, health system leaders) [140-142]. Trainees involved in IKT research are encouraged to apply these qualitative and quantitative methods to evaluate their IKT approach and contribute to the growing body of evidence on IKT impacts and outcomes [143].

\section{Summary of implications}

Findings from our review address two of the four main goals of scoping reviews [22]: (1) examine the extent, range and nature of the research activity; and (2) identify research gaps in the existing literature. First, this study mapped what is known about trainee-led IKT and partnership research in the literature. Our findings highlight that more formal training efforts may be needed to support skill development for research trainees involved in partnership research. Further, our findings build on previous IKT work highlighting the need for organizational resources and policies to support research partnership approaches.

Second, this review identified research gaps in the existing IKT literature. To advance our understanding of IKT principles and strategies and how trainees partner with knowledge users, we recommend clearly articulating specific activities used in each level of engagement. These details would help trainees to plan knowledge user engagement during their research projects, including the feasibility and utility of different levels of engagement, and would help to understand differences among types of knowledge users. Further, while the included studies described IKT and research partnership approaches, it was not clear why trainees embark on IKT. Additional empirical research is needed to understand the trainees' motivations for using an IKT approach in their research. This type of research should also aim to understand the unintended consequences of IKT and the power dynamics experienced by trainees and knowledge users, and to identify strategies to promote authentic collaboration, power-sharing and co-creation of knowledge. Lastly, our findings highlight the need for more evaluation of IKT and partnership approaches. We recommend that trainees evaluate their IKT approach and contribute to the growing body of evidence on IKT impacts and outcomes.

\section{Limitations}

Several limitations may affect the interpretation and use of our review findings. First, although we built our search strategy from an umbrella review of IKT and research partnership reviews [144], partnership research is a broad phenomenon. We narrowed our focus to IKT approaches or similar research partnerships that focused on working with knowledge users throughout the health research process. However, IKT is predominantly a Canadian term, and we may have missed papers that described research partnerships differently or in a language other than English. This may be why no papers were identified from lower- and middle-income countries. Second, we only included papers that were written by trainees. Although we conducted a followup search of the author's information to identify trainee status, it is possible that we may have missed papers and did not capture all trainees who have used an IKT or other research partnership approaches in their work. Third, many papers lacked detail on the IKT principles and strategies, which made it challenging to analyse the IKT approach using the WIDER [32] reporting checklist. A specific reporting guideline for this type of work is needed to improve reporting and understanding of the IKT approach, including level-of-knowledge user engagement and IKT strategies. Fourth, we categorized the barriers and facilitators into three levels (individual, interpersonal, organizational) to aid in interpreting how the individual trainee is situated within the academichealth system. These categories are not absolute; many barriers and facilitators exist across the three levels and could be categorized differently depending on the context. Lastly, we found that a quarter of included papers did not evaluate their IKT approach outcome of partnership formation. However, it is important to note that our focus was on the IKT trainee experience and not specifically on evaluation of IKT. These types of evaluation studies may have been published separately and at a later 
date, as the impact of IKT projects can take years to be fully realized and evaluated.

\section{Conclusions}

This scoping review of 74 papers describes how health research trainees have used an IKT or other research partnership approach in their research. Most trainees have collaborated with knowledge users in the research question development, recruitment and data collection research stages. We identified key barriers and facilitators related to individual, interpersonal and organizational factors. Findings illustrate the importance of having specific knowledge and skills to engage in research partnerships, interpersonal influences of supervisors and knowledge users, and institutional support for a different way of working in graduate and postgraduate work. We also identified enhanced relevance of research findings as an important outcome of IKT trainee research. These review findings can serve as a basis for future reviews and primary research focused on IKT principles, strategies and evaluation. Further, we expect these findings can be used to inform IKT training efforts including trainee guideline development and academic-health system research supports.

\section{Abbreviations}

IKT: Integrated knowledge translation; IKTRN: Integrated Knowledge Translation Research Network; KT: Knowledge translation; COM-B: Capability, Opportunity, and Motivation-Behaviour; TDF: Theoretical Domains Framework; WIDER: Workgroup for Intervention Development and Evaluation Research; JBI: Joanna Briggs Institute.

\section{Supplementary Information}

The online version contains supplementary material available at https://doi. org/10.1186/s12961-021-00784-0.

Additional file 1. Search strategy.

Additional file 2. PRISMA_SCR Checklist.

\section{Acknowledgements}

We wish to thank the Integrated Knowledge Translation Research Network for their support of this study.

\section{Authors' contributions \\ $C C, A B, A C, M D V, C L, E R$, TN and SS designed the scoping review protoco including data collection and interpretation planning. CC, HDS, KM, ER, SS, CL, $M D V$ and $J L$ performed the title and abstract and full-text screening. CC, HDS, $T N, A B, M D V, A C, J L, R D$ and LD performed data extraction. CC and HDS con- ducted data analysis, and the full team participated in data interpretation. CC and HDS wrote the first draft of the manuscript. All authors critically reviewed and revised the manuscript and approved the final version.}

\section{Funding}

Not applicable.

\section{Availability of data and materials}

All data generated or analysed during this study are included in this published article and its additional information files.

\section{Declarations}

Ethics approval and consent to participate Not applicable.

\section{Consent for publication}

Not applicable.

\section{Competing interests}

The authors declare that they have no competing interests.

\section{Author details}

${ }^{1}$ School of Nursing, Dalhousie University, Halifax, NS, Canada. ${ }^{2}$ School of Health Sciences, University of Newcastle, Callaghan, Australia. ${ }^{3}$ Better Outcomes and Registry Network (BORN), Ottawa, ON, Canada. ${ }^{4}$ Alberta Health Services Foothills Medical Centre, Calgary, AB, Canada. ${ }^{5}$ Institute for Health System Solutions and Virtual Care, Women's College Hospital, Toronto, Canada. ${ }^{6}$ Faculty of Nursing, University of Calgary, Calgary, AB, Canada. ${ }^{7}$ School of Nursing, University of Ottawa, Ottawa, ON, Canada. ${ }^{8}$ Health Information Science, Western University, London, ON, Canada. ${ }^{9}$ School of Epidemiology and Public Health, University of Ottawa, Ottawa, ON, Canada. ${ }^{10} \mathrm{School}$ of Health and Human Performance, Dalhousie University, Halifax, NS, Canada. ${ }^{11}$ Dalhousie University, Halifax, NS, Canada. ${ }^{12}$ Department of Family Medicine, McGill University, Montreal, QC, Canada.

Received: 22 June 2021 Accepted: 12 October 2021

Published online: 02 November 2021

\section{References}

1. Rycroft-Malone J, Burton CR, Wilkinson J, Harvey G, McCormack B, Baker R, et al. Collective action for implementation: a realist evaluation of organisational collaboration in healthcare. Implement Sci. 2016;11:17.

2. Kothari A, McCutcheon C, Graham ID. Defining integrated knowledge translation and moving forward: a response to recent commentaries. Int J Health Policy Manag. 2017;6:299-300.

3. Oliver K, Kothari A, Mays N. The dark side of coproduction: do the costs outweigh the benefits for health research? Health Res Policy Syst. 2019;17:33.

4. Gagliardi AR, Berta W, Kothari A, Boyko J, Urquhart R. Integrated knowledge translation (IKT) in health care: a scoping review. Implement Sci. 2016;11:38.

5. Jagosh J, Macaulay AC, Pluye P, Salsberg J, Bush PL, Henderson J, et al. Uncovering the benefits of participatory research: implications of a realist review for health research and practice. Milbank Q. 2012;90:311-46.

6. Jessani NS, Valmeekanathan A, Babcock C, Ling B, Davey-Rothwell MA, Holtgrave DR. Exploring the evolution of engagement between academic public health researchers and decision-makers: from initiation to dissolution. Health Res Policy Syst. 2020;18:15.

7. Walter I, Davies H, Nutley S. Increasing research impact through partnerships: Evidence from outside health care. J Health Serv Res Policy. 2003;8(2_suppl):58-61.

8. Hofmeyer A, Scott C, Lagendyk L. Researcher-decision-maker partnerships in health services research: practical challenges, guiding principles. BMC Health Serv Res. 2012;12:280-280.

9. Bowen S, Botting I, Graham ID. Re-imagining health research partnership in a post-COVID world: a response to recent commentaries. Int J Health Policy Manag. 2020. http://www.ijhpm.com/article_3810.html.

10. Nyström ME, Karltun J, Keller C, Andersson GB. Collaborative and partnership research for improvement of health and social services: researcher's experiences from 20 projects. Health Res Policy Syst. 2018. https://doi.org/ 10.1186/s12961-018-0322-0.

11. Bowen S, Botting I, Graham ID, MacLeod M, De Moissac D, Harlos K, et al. Experience of health leadership in partnering with university-based researchers in Canada_-a call to "re-imagine" research. Int J Health Policy Manag. 2019;8:684-99.

12. Barratt H, Shaw J, Simpson L, Bhatia S, Fulop N. Health services research: building capacity to meet the needs of the health care system. J Health Serv Res Policy. 2017;22:243-9. 
13. McMahon M, Bornstein S, Brown A, Simpson LA, Tamblyn LS, R. Training for health system improvement: emerging lessons from Canadian and US approaches to embedded fellowships. Healthc Policy. 2019;(15)34-48.

14. Bornstein S, Heritage M, Chudak A, Tamblyn R, McMahon M, Brown AD. Development of enriched core competencies for health services and policy research. Health Serv Res. 2018;53(Suppl 2):4004-23.

15. Cassidy CE, Bowen S, Fontaine G, Côté-Boileau É, Botting I. How to work collaboratively within the health system: workshop summary and facilitator reflection. Int J Health Policy Manag. 2019. http://www.ijhpm.com/article_ 3717.html.

16. Antes AL, Kuykendall A, DuBois JM. Leading for research excellence and integrity: a qualitative investigation of the relationship-building practices of exemplary principal investigators. Account Res. 2019;26:198-226.

17. Zych MM, BertaWB, Gagliardi AR. Conceptualising the initiation of researcher and research user partnerships: a meta-narrative review. Health Res Policy Syst. 2020;18:24

18. Zych MM, Berta WB, Gagliardi AR. Initiation is recognized as a fundamental early phase of integrated knowledge translation (IKT): qualitative interviews with researchers and research users in IKT partnerships. BMC Health Serv Res. 2019:19:772-772.

19. Sibbald SL, Kang H, Graham ID. Collaborative health research partnerships: a survey of researcher and knowledge-user attitudes and perceptions. Health Res Policy Syst. 2019;17:92.

20. Peters M, Godfrey C, McInerney P, Baldini Soares C, Khalil H, Parker D. Chapter 11: Scoping Reviews. In: Aromataris E, Munn Z, editors. Joanna Briggs Institute reviewer's manual. The Joanna Briggs Institute; 2017. https://revie wersmanual.joannabriggs.org/.

21. Peters MDJ, Marnie C, Tricco AC, Pollock D, Munn Z, Alexander L, et al. Updated methodological guidance for the conduct of scoping reviews. JBI Evid Synth. 2020. https://doi.org/10.11124/JBIES-20-00167.

22. Arksey H,O'Malley L. Scoping studies: towards a methodological framework. Int J Soc Res Methodol. 2005;8:19-32.

23. Cassidy CE, Beck AJ, Conway A, Varin MD, Laur C, Lewis KB, et al. Using an integrated knowledge translation or other research partnership approach in trainee-led research: a scoping review protocol. BMJ Open. 2021;11: e043756.

24. Tricco AC, Lillie E, Zarin W, O'Brien KK, Colquhoun H, Levac D, et al. PRISMA extension for scoping reviews (PRISMA-SCR): checklist and explanation. Ann Intern Med. 2018;169:467-73.

25. +Government of Canada Cl of HR. Health Research in Canada and YouCIHR. 2011. https://cihr-irsc.gc.ca/e/43753.html.

26. Institute of Medicine. Beyond the HIPAA privacy rule: enhancing privacy, improving health through research. Washington, DC: The National Academies Press; 2009. https://doi.org/10.17226/12458.

27. Hoekstra F, Mrklas KJ, Khan M, McKay RC, Vis-Dunbar M, Sibley KM, et al. A review of reviews on principles, strategies, outcomes and impacts of research partnerships approaches: a first step in synthesising the research partnership literature. Health Res Policy Syst. 2020;18:1-23.

28. Covidence systematic review software. Melbourne, Australia; 2019. www. covidence.org.

29. Graham ID, Logan J, Harrison MB, Straus SE, Tetroe J, Caswell W, et al. Lost in knowledge translation: time for a map? J Contin Educ Health Prof. 2006:26:13-24.

30. International Association for Public Participation (IAP2)). Core values, ethics, spectrum - the 3 pillars of public participation - International Association for Public Participation. https://www.lap2.org/page/pillars.

31. Dillon EC, Tuzzio L, Madrid S, Olden H, Greenlee RT. Measuring the impact of patient-engaged research: how a methods workshop identified critical outcomes of research engagement. J Patient-Centered Res Rev. 2017:4:237-46.

32. Albrecht L, Archibald M, Arseneau D, Scott SD. Development of a checklist to assess the quality of reporting of knowledge translation interventions using the Workgroup for Intervention Development and Evaluation Research (WIDER) recommendations. Implement Sci. 2013;8:52.

33. Michie, Atkins, West. The behaviour change wheel: a guide to designing interventions. London: Silverback Publishing. www.behaviourchange wheel.com; 2014.

34. Atkins L, Francis J, Islam R, O'Connor D, Patey A, Ivers N, et al. A guide to using the theoretical domains framework of behaviour change to investigate implementation problems. Implement Sci. 2017;12:77.
35. McLeroy KR, Bibeau D, Steckler A, Glanz K. An ecological perspective on health promotion programs. Health Educ Q. 1988;15:351-77.

36. Gagliardi AR, Kothari A, Graham ID. Research agenda for integrated knowledge translation (IKT) in healthcare: what we know and do not yet know. Epidemiol Community Health. 2017;71:105.

37. Abdul Qader SA, King ML. Transcultural adaptation of best practice guidelines for ostomy care: pointers and pitfals. Middle East J Nurs. 2015;9:3-12.

38. Abelsohn KA, Ferne JM, Scanlon KA, Giambrone BL, Bomze SB. "About time!" Insights from research with pride: a community-student collaboration. Health Promot Int. 2012;27:372-81.

39. Atherton M, Davidson B, McAllister L. Building collaboration. J Clin Pract Speech-Lang Pathol. 2016;18:108-15.

40. Gibbon M. Doing a doctorate using a participatory action research framework in the context of community health. Qual Health Res. 2002;12:546-58.

41. Gilhooly D, Lynn CA. Karen resettlement: a participatory action research project. J Int Migr Integr. 2015;16:799-817.

42. Goessling K, Doyle C. Thru the Lenz: participatory action research, photography, and creative process in an urban high school. J Creat Ment Health. 2009:4:343-65.

43. Bloodworth M, Kapungu C, Majer J, McDonald K, Sharma A, Viola J, et al. Student reflections on community research practices and their implications. In: Participatory community research: theories and methods in action. Washington, DC: American Psychological Association; 2004. p. 227-38. https://doi.org/10.1037/10726-014.

44. Burgess J. Participatory action research: first-person perspectives of a graduate student. Action Res. 2006:4:419-37.

45. Cassidy CE, Burgess S, Graham ID. It's all about the IKT approach: three perspectives on an embedded research fellowship comment on "CIHR health system impact fellows: reflections on 'driving change' within the health system." Int J Health Policy Manag. 2019;8:455-8.

46. Cindy Smithers G, Mandawe E. Indigenous geographies: research as reconciliation. Int Indig Policy J. 2017:8(2)

47. DeLemos J, RockT, Brugge D, Slagowski N, Manning T, Lewis J. Lessons from the Navajo: assistance with environmental data collection ensures cultural humility and data relevance. Prog Community Health Partnersh Res Educ Action. 2007;1:321-6.

48. Nadimpalli SB, Van Devanter N, Kavathe R, Islam N. Developing and conducting a dissertation study through the community-based participatory research approach. Pedagogy Health Promot. 2016;2:94-100.

49. Leslie JH, Hughes CK, Braun KL. Engaging participants in design of a Native Hawaiian worksite wellness program. Prog Community Health Partnersh Res Educ Action. 2010;4:121-30.

50. Schuch JC. Community-academic partnerships to improve Hispanic immigrant health: perspectives from a doctoral student. Narrat Inq Bioeth. 2017;7:18-21.

51. Shelton NJ. Applying sociology through participation and cooperative knowledge creation. Southeastern Louisiana University; 2011.

52. Wilbricht J.Theengaged dissertation-conducting community-based participatory research with rural indigenous communities as a graduate student. Narrat Inq Bioeth. 2017;7:33-6.

53. Ormel I, Law S. Piloting co-design in a humanitarian setting: new insights and lessons learnedthe importance of cultural and contextual adaptation. IKTRN Trainee Casebook. 2020;3:19-21.

54. Canadian Association of Graduate Studies. Non-traditional dissertation profile: Sarah Munro 2018 | Rethinking the PhD. 2018. https://cags.ca/proje cts/rethinking-profiles/sarah-munro/.

55. Videmšek P, Fox J. Exploring the value of involving experts-by-experience in social work research: experiences from Slovenia and the UK. Eur I Soc Work. 2018;21:498-508.

56. Donnelly CA. Evaluation as a mechanism for integrated knowledge translation. Queen's University (Canada); 2013

57. Hilario CT. Applying integrated knowledge translation to address mental health among young immigrant and refugee men in Canada. 2018. https:/open.library.ubc.ca/collections/24/items/1.0368796.

58. Wine O, Ambrose S, Campbell S, Villeneuve PJ, Burns KK, Vargas AO. Key Components of collaborative research in the context of environmental health: a scoping review. J Res Pract. 2017;13(2)

59. Jervis J. Real voices : a participatory action research study to explore the support provided to children visiting adult patients in h. Keele University (United Kingdom); 2019. 
60. Volpe LE. "Health is Being Alive": Using Photovoice to Explore Adolescents' Conceptions of Health Ohio University; 2017.

61. Maher BL. Decolonising public health: applying epidemiology and indigenous worldview to how health and well-being is considered by aboriginal and Torres Strait Islander People. The Australian National University (Australia); 2019.

62. Jones R. The epidemiology of Aboriginal and Torres Strait Islander culture, health and wellbeing. The Australian National University (Australia); 2019.

63. McCaig M. Exploring and developing positive experiences of values-based practice in an acute mental health ward using appreciative act. University of the West of Scotland (United Kingdom); 2019.

64. Jones AC. Exploring Ugandan secondary school students'sexual health education needs and developing school-based sexual health interventions through participatory action research. University of Alberta (Canada); 2012.

65. Hohn MD. Partnering for empowerment health education in adult literacy: a single site case study using participatory action research with a student action health team. The Fielding Institute; 1998.

66. Murdoch M. Examining participatory action research involving women with disabilities: partnership, perspective and power. Memorial University of Newfoundland (Canada); 2006.

67. Burgess J. Finding a balance: participatory action research with primary health care nurse practitioners on the relevance of collaboration to nurse practitioner role integration. University of Victoria (Canada); 2009.

68. Allen D, Hutchinson T. Using PAR or abusing its good name? the challenges and surprises of photovoice and film in a study of chronic illness. Int J Qual Methods. 2009:8:115-28.

69. Baukus AJ. Developing a community-based research project proposal to build public health educator capacity: a graduate student perspective. Health Promot Pract. 2019;20:801-4.

70. Khobzi N, Flicker S. Lessons learned from undertaking community-based participatory research dissertations: the trials and triumphs of two junior health scholars. Prog Community Health Partnersh Res Educ Action. 2010;4:347-56.

71. Gonzalez JV. Latino immigrant parents of English language learner students, school involvement and the participation breach. Ann Arbor: University of San Francisco; 2012.

72. Haywood C, Martinez G, Pyatak EA, Carandang K. Engaging patient stakeholders in planning, implementing, and disseminating occupational therapy research. Am J Occup Therapy. 2019;73:7301090010p1-9.

73. Moll S, Clements EP. Workplace mental health: developing an employer resource through partnerships in knowledge translation. Occup Therapy Now. 2008;10:17-9.

74. Lac VT, Fine M. The good, the bad, and the ugly: an autoethnographic journey on doing participatory action research as a graduate student. Urban Educ. 2018;53:562-83.

75. MedcalfTC. The reality beyond appearances: elders on growing old. ProQuest Information and Learning; 2008.

76. van der Meulen E. Participatory and action-oriented dissertations: the challenges and importance of community-engaged graduate research. Qual Rep. 2011;16:1291-303.

77. Lewis KB, Stacey D, Carroll SL, Birnie D. Development of a patient decision aid to accept or decline implantable cardioverter-defibrillator replacement: an example of integrated knowledge translation in $\mathrm{PhD}$ research. IKTRN Casebook. 2020;2:7-9.

78. Cassidy C, Foley L, Rowe M, Best S, Curran JA. Fostering an academic-clinical partnership to redesign care on a pediatric inpatient unit. IKTRN Trainee Casebook. 2020;1:29-30.

79. Laur C, Butterworth D, Nasser R, Stickles-White M, Tom M, Keller H. Working with hospital teams to treat food as medicine. IKTRN Trainee Casebook. 2020;3:4-7.

80. Ramage ER, Meredith B, Galloway M, Janssen H, Lynch E, Marsden DL, et al. An integrated knowledge translation approach to co-design a complex exercise intervention for stroke survivors: a case report. IKTRN Trainee Casebook. 2020;3:13-7.

81. Conway A, Dowling M, Binchy Á, Grosvenor J, Coohill M, Naughton D, et al. Working together towards impact: An integrated knowledge translation initiative aimed at health-care providers. IKTRN Trainee Casebook. 2020;3:22-5.

82. Kinman RAP. Creating high school change agents to improve adolescent health: creation of a collaborative partnership between a pediatric residency program and at-risk youth. Fresno: California State University; 2017.

83. Oosman SN. Kica-Wasimisinanahk Miyo-ayawin—our children's health. Promoting physical activity and nutrition through a health promoting schoolbased intervention in a métis community. The University of Saskatchewan (Canada); 2012.

84. Reale VN. Integrating health promoting principles into the context of a standards based high school: an autobiographical action research case study. University of Hull (United Kingdom); 2011.

85. McHugh T-LF."a new view of body image": a school-based participatory action research project with young Aboriginal women. The University of Saskatchewan (Canada); 2008.

86. Blum CA. Development of an undergraduate preceptor model of practice education for nursing students utilizing participatory action research. Florida Atlantic University; 2006.

87. Lind C. The power of adolescent voices: interpretations of adolescent participation as co-researchers in mental health promotion. University of Calgary (Canada); 2006.

88. Ramstetter CL. Participatory action research to assess and enhance coordinated school health in one elementary school. University of Cincinnati; 2010

89. Bellows Riecken KH. Reading into physical activity: exploring relationships between health literacy and physical activity in the community. University of Victoria (Canada); 2012.

90. Suderman K, Dolgoy N, Yurick J, Sellar C, Nishimura K, Culos-Reed SN, et al. A practical approach to using integrated knowledge translation to inform a community-based exercise study. Int J Env Res Public Health. 2020. https://doi.org/10.3390/ijerph17113911.

91. Dunn M, Drew C, O'Brien J, Wood M, Mora E, Diener S, et al. A communityacademic partnership for school-based nonviolence education: the healthy power program. J Sch Health. 2020;90:65-9.

92. Jull J, Hizaka A, Sheppard AJ, Kewayosh A, Doering P, MacLeod L, et al. An integrated knowledge translation approach to develop a shared decisionmaking strategy for use by Inuit in cancer care: a qualitative study. Curr Oncol. 2019. https://doi.org/10.3747/co.26.4729.

93. Campbell BR. Participatory action research: knowledge translation of children's health in a rural community. University of Calgary (Canada); 2006.

94. Robinson PA. Mental health research: a path to personal, interpersonal, and political change for participant researchers? Memorial University of Newfoundland (Canada); 2007.

95. Bowyer SE. Participatory mapping as an approach for health services coplanning: finding the local voice in the rural context. University of the Highlands and the Islands (United Kingdom); 2018.

96. Lillehagen I. Participatory research as knowledge translation strategy. An ethnographic study of knowledge co-creation. 2017. https://www.duo. uio.no/handle/10852/55513.

97. Bishop AC, Elliott MJ, Cassidy C. Moving patient-oriented research forward: thoughts from the next generation of knowledge translation researchers. Res Involv Engagem. 2018;4:23.

98. Winners of the CHIPS/CAHSPR Student Competition 2016-IKT Research Network. https://iktrn.ohri.ca/winners-of-the-chipscahspr-student-compe tition-2016/.

99. Sanderson V, Vandyk A, Jacob JD, Graham ID. Engaging knowledge users with mental health experience in a mixed-methods systematic review of post-secondary students with psychosis: reflections and lessons learned from a master's thesis. Int J Health Policy Manag. 2020. https://doi.org/10. 34172/ijhpm.2020.138.

100. Boland L. A doctoral student perspective about using integrated knowledge translation to evaluate a pediatric shared decision-making program. IKTRN Trainee Casebook. 2020;3:9-12.

101. Sim SM, Lai J, Aubrecht K, Cheng I, Embrett M, Ghandour EK, et al. CIHR health system impact fellows: reflections on "driving change" within the health system. Int J Health Policy Manag. 2019;8:325-8.

102. Mitchell FM. Engaging in indigenous CBPR within academia: a critical narrative. Affil J Women Soc Work. 2018;33:379-94.

103. DeWitt NT. It takes a community to change a broken system: Using an interorganizational collaborative group to help ensure all Oakland students graduate from high school. Ann Arbor: University of San Francisco; 2011.

104. Dalal M, Skeete R, Yeo HL, Lucas GI, Rosenthal MS. A physician team's experiences in community-based participatory research: insights into effective group collaborations. Am J Prev Med. 2009;37(6 Suppl 1):S288-291. 
105. Björnsdóttir K, Svensdóttir AS. Gambling for capital: learning disability, inclusive research and collaborative life histories. Br J Learn Disabil. 2008:36:263-70.

106. Fletcher AJ, Marchildon GP. Using the Delphi method for qualitative, participatory action research in health leadership. Int I Qual Methods. 2014;13:1-18.

107. Fletcher AJ, Marchildon GP. Reflection/commentary on a past article:"using the delphi method for qualitative research in health leadership." Int J Qual Methods. 2018. https://doi.org/10.1177/1609406918788252.

108. Pratt H, Mackay M, Green C, Woodhouse G, Marriott-Statham K. Courageous collaboration in co-constructing learning and teaching resources. Int Pract Dev J. 2019;9:1-6.

109. Roberts EB, Jette SL. Implementing participatory research with an urban American Indian community: lessons learned. Health Educ J. 2016;75:158-69.

110. Feroz BA. Exploring the meaning of power and voice through a participatory action research project conducted by a doctoral student. Indiana University of Pennsylvania; 2009.

111. IAP2Canada-publicparticipationspectrum.https://cdn.ymaws.com/www. iap2.org/resource/resmgr/pillars/Spectrum_8.5x11_Print.pdf

112. Kothari A, Wathen CN. A critical second look at integrated knowledge translation. Health Policy. 2013;109:187-91.

113. Nguyen T, Graham ID, Mrklas KJ, Bowen S, Cargo M, Estabrooks CA, et al. How does integrated knowledge translation (IKT) compare to other collaborative research approaches to generating and translating knowledge? Learning from experts in the field. Health Res Policy Syst. 2020;18:35.

114. Vindrola-Padros C. Can We Re-Imagine Research So It Is Timely, Relevant and Responsive?; Comment on "Experience of Health Leadership in Partnering with University-Based Researchers in Canada: A Call to'Re-Imagine' Research". Int J Health Policy Manag. 2021;10(3):172-5. https://doi.org/10 34172/ijhpm.2020.43.

115. Rycroft-Malone J. The PARIHS framework - a framework for guiding the implementation of evidence-based practice. J Nurs Care Qual. 2004; 19:297.

116. Berta W, Cranley L, Dearing JW, Dogherty EJ, Squires JE, Estabrooks CA. Why (we think) facilitation works: insights from organizational learning theory. Implement Sci. 2015;10:141.

117. Harvey G, Loftus-Hills A, Rycroft-Malone J,Titchen A, Kitson A, McCormackB, et al. Getting evidence into practice: the role and function of facilitation. J Adv Nurs. 2002;37:577-88.

118. Mallidou AA, Atherton P, Chan L, Frisch N, Glegg S, Scarrow G. Core knowledge translation competencies: a scoping review. BMC Health Serv Res. 2018;18:502.

119. Straus SE, Brouwers $M$, Johnson D, Lavis JN, Légaré F, Majumdar SR, et al. Core competencies in the science and practice of knowledge translation: description of a Canadian strategic training initiative. Implement Sci. 2011;6:127.

120. Bornstein S, Heritage M, Chudak A, Tamblyn R, McMahon M, Brown AD. Development of enriched core competencies for health services and policy research. Health Serv Res. 2018;53:4004-23.

121. Canadian Institutes of Health Research. CIHR health system impact fellowship. 2018. https://www.researchnet-recherchenet.ca.

122. Academy Health. AcademyHealth's Delivery System Science Fellowship: training embedded researchers to design, implement, and evaluate new models of care | J Hosp Med. https://www.journalofhospitalmedicine. com/jhospmed/article/142061/hospital-medicine/academyhealths-deliv ery-system-science-fellowship-training.

123. Dwyer SC, Buckle JL. The space between: on being an insider-outsider in qualitative research. Int J Qual Methods. 2009;8:54-63.

124. Burns E, Fenwick J, Schmied V, Sheehan A. Reflexivity in midwifery research: the insider/outsider debate. Midwifery. 2012;28:52-60.

125. HillT,Dao M. Personal pasts becomeacademic presents:engaging reflexivity and considering dual insider/outsider roles in physical cultural fieldwork. Qual Res Sport Exerc Health. 2021:13:521-35.

126. Cosgrove D, Kramer CS, Mountz S, Lee E. The role of identity in motivating and shaping the experiences of social work participatory action research scholars. Affilia. 2020;35:552-71.

127. Secules S, McCall C, Mejia JA, Beebe C, Masters AS, Sánchez-Peña ML, et al. Positionality practices and dimensions of impact on equity research: a collaborative inquiry and call to the community. J Eng Educ. 2021;110:19-43.
128. Stamatakis KA, Norton WE, Stirman SW, Melvin C, Brownson RC. Developing the next generation of dissemination and implementation researchers: insights from initial trainees. Implement Sci. 2013;8:29.

129. Canas E, Shoemaker JK, Kothari A. Promising Points for Intervention in Re-Imagining Partnered Research in Health Services Comment on "Experience of Health Leadership in Partnering with University-Based Researchers in Canada - A Call to 'Re-imagine' Research". Int J Health Policy Manag. 2021;10(3):155-7.

130. Wilkins $\mathrm{CH}$. Effective engagement requires trust and being trustworthy. Med Care. 2018:56(10 Suppl 1):S6-8.

131. Crosschild C, Huynh N, De Sousa I, Bawafaa E, Brown H. Where is critical analysis of power and positionality in knowledge translation? Health Res Policy Syst. 2021;19:92

132. Bowen S. Should we be teaching researchers humility? Literature review and reflection. Ottawa, ON: Integrated Knowledge Translation Research Network; 2020.

133. Owens BP, Johnson MD, Mitchell TR. Expressed humility in organizations: implications for performance, teams, and leadership. Organ Sci. 2013;24:1517-38.

134. Davis DE, Rice K, McElroy S, DeBlaere C, Choe E, Van Tongeren DR, et al. Distinguishing intellectual humility and general humility. J Posit Psychol. 2016:11:215-24

135. Cassidy CE, Burgess S, Graham ID. It's all about the IKT approach: three perspectives on an embedded research fellowship; comment on "CIHR health system impact fellows: reflections on'driving change' within the health system." Int J Health Policy Manag. 2019;8:455-8.

136. Lal S, Urquhart R, Cornelissen E, Newman K, Van Eerd D, Powell BJ, et al. Trainees'self-reported challenges in knowledge translation, research and practice. Worldviews Evid Based Nurs. 2015:12:348-54.

137. Bucknall TK, Hutchinson AM. Cultivating value co-creation in health system research. 3.

138. Kreindler SA. Advancing the evaluation of integrated knowledge translation. Health Res Policy Syst. 2018;16:104.

139. Pawson R, Tilley N. Realistic evaluation. Thousand Oaks: SAGE; 1997.

140. Boivin A, L'Espérance A, Gauvin F-P, Dumez V, Macaulay AC, Lehoux P, et al. Patient and public engagement in research and health system decision making: a systematic review of evaluation tools. Health Expect Int J Public Particip Health Care Health Policy. 2018;21:1075-84.

141. Abelson J, Li K, Wilson G, Shields K, Schneider C, Boesveld S. Supporting quality public and patient engagement in health system organizations: development and usability testing of the Public and Patient Engagement Evaluation Tool. Health Expect Int J Public Particip Health Care Health Policy. 2016;1 19:817-27.

142. Kreindler SA, Struthers A. Assessing the organizational impact of patient involvement: a first STEPP. Int J Health Care Qual Assur. 2016;29:441-53.

143. Hoekstra F, Mrklas KJ, Khan M, McKay RC, Vis-Dunbar M, Sibley KM, et al. A review of reviews on principles, strategies, outcomes and impacts of research partnerships approaches: a first step in synthesising the research partnership literature. Health Res Policy Syst. 2020;18:51.

144. Hoekstra F, Mrklas KJ, Sibley KM, Nguyen T, Vis-Dunbar M, Neilson CJ, et al. A review protocol on research partnerships: a coordinated multicenter team approach. Syst Rev. 2018;7:217.

145. Barrier noun—Definition, pictures, pronunciation and usage notes | Oxford Advanced Learner's Dictionary at OxfordLearnersDictionaries.com. Oxford Learner's Dictionary. https://www.oxfordlearnersdictionaries.com/defin ition/english/barrier?q=barrier.

146. Definition ofFacilitator.MerriamWebster's Dictionary.https://www.merriamwebster.com/dictionary/facilitator.

147. Michie S, van Stralen MM, West R. The behaviour change wheel: a new method for characterising and designing behaviour change interventions. Implement Sci. 2011;6:42.

148. Cane J, O'Connor D, Michie S. Validation of the theoretical domains framework for use in behaviour change and implementation research. Implement Sci. 2012:7:37.

\section{Publisher's Note}

Springer Nature remains neutral with regard to jurisdictional claims in published maps and institutional affiliations. 